\title{
Article \\ Computational Insights on the Potential of Some NSAIDs for Treating COVID-19: Priority Set and Lead Optimization
}

\author{
Ayman Abo Elmaaty ${ }^{1}$, Mohammed I. A. Hamed ${ }^{2}$, Muhammad I. Ismail $^{3}\left(\mathbb{D}\right.$, Eslam B. Elkaeed ${ }^{4,5}$ (D), \\ Hamada S. Abulkhair ${ }^{5,6}\left(\mathbb{D}\right.$, Muhammad Khattab ${ }^{7}$ and Ahmed A. Al-Karmalawy ${ }^{6, *(D)}$
}

1 Department of Medicinal Chemistry, Faculty of Pharmacy, Port Said University, Port Said 42526, Egypt; ayman.mohamed@pharm.psu.edu.eg

2 Department of Organic and Medicinal Chemistry, Faculty of Pharmacy, Fayoum University, Fayoum 63514, Egypt; mia06@fayoum.edu.eg

3 Department of Pharmaceutical Chemistry, Faculty of Pharmacy, The British University in Egypt, Cairo-Suez Desert Road, Cairo 11837, Egypt; m.ismail.800@gmail.com

4 Department of Pharmaceutical Sciences, College of Pharmacy, AlMaarefa University, Ad Diriyah, Riyadh 13713, Saudi Arabia; ikaeed@mcst.edu.sa

5 Pharmaceutical Organic Chemistry Department, Faculty of Pharmacy (Boys), Al-Azhar University, Nasr City, Cairo 11884, Egypt; habulkhair@horus.edu.eg

6 Department of Pharmaceutical Chemistry, Faculty of Pharmacy, Horus University-Egypt, New Damietta 34518, Egypt

7 Department of Chemistry of Natural and Microbial Products, Division of Pharmaceutical and Drug Industries, National Research Centre, Cairo 12622, Egypt; mkhattab@swin.edu.au

* Correspondence: akarmalawy@horus.edu.eg; Tel.: +20-1092147330

check for updates

Citation: Abo Elmaaty, A.; Hamed, M.I.A.; Ismail, M.I.; B. Elkaeed, E.; S. Abulkhair, H.; Khattab, M.; Al-Karmalawy, A.A. Computational Insights on the Potential of Some NSAIDs for Treating COVID-19: Priority Set and Lead Optimization. Molecules 2021, 26, 3772. https:// doi.org/10.3390/molecules26123772

Academic Editor: Teobald Kupka

Received: 22 May 2021

Accepted: 11 June 2021

Published: 21 June 2021

Publisher's Note: MDPI stays neutral with regard to jurisdictional claims in published maps and institutional affiliations.

Copyright: (c) 2021 by the authors. Licensee MDPI, Basel, Switzerland. This article is an open access article distributed under the terms and conditions of the Creative Commons Attribution (CC BY) license (https:/ / creativecommons.org/licenses/by/ $4.0 /)$.

\begin{abstract}
The discovery of drugs capable of inhibiting SARS-CoV-2 is a priority for human beings due to the severity of the global health pandemic caused by COVID-19. To this end, repurposing of FDAapproved drugs such as NSAIDs against COVID-19 can provide therapeutic alternatives that could be utilized as an effective safe treatment for COVID-19. The anti-inflammatory activity of NSAIDs is also advantageous in the treatment of COVID-19, as it was found that SARS-CoV-2 is responsible for provoking inflammatory cytokine storms resulting in lung damage. In this study, 40 FDA-approved NSAIDs were evaluated through molecular docking against the main protease of SARS-CoV-2. Among the tested compounds, sulfinpyrazone 2, indomethacin 3, and auranofin 4 were proposed as potential antagonists of COVID-19 main protease. Molecular dynamics simulations were also carried out for the most promising members of the screened NSAID candidates $(2,3$, and 4$)$ to unravel the dynamic properties of NSAIDs at the target receptor. The conducted quantum mechanical study revealed that the hybrid functional B3PW91 provides a good description of the spatial parameters of auranofin 4. Interestingly, a promising structure-activity relationship (SAR) was concluded from our study that could help in the future design of potential SARS-CoV-2 main protease inhibitors with expected anti-inflammatory effects as well. NSAIDs may be used by medicinal chemists as lead compounds for the development of potent SARS-CoV-2 (Mpro) inhibitors. In addition, some NSAIDs can be selectively designated for treatment of inflammation resulting from COVID-19.
\end{abstract}

Keywords: drug repurposing; SARS-CoV-2 main protease; docking; molecular dynamics; DFT calculations

\section{Introduction}

In December 2019, a novel coronavirus disease (COVID-19) was detected initially in China. The virus outbreak took place first in Wuhan city and continued to spread worldwide. After the virus's terrible breakthrough, the World Health Organization assessed that COVID-19 was a pandemic on 11 March 2020 [1]. By 11 April 2021, approximately $136,781,961$ patients were diagnosed with COVID-19, affecting 221 countries and territories around the world with a total death toll of 2,951,955 [2]. The virus is highly contagious and lethal, especially for those with other health issues [3]. 
Inflammatory cytokine storm is a very common critical symptom in patients with severe COVID-19, leading to systemic inflammation and high multiple organ failure [3]. Unfortunately, there are no effective drugs-to date-that can treat COVID-19. On the other hand, the development of a new drug is not a facile process and needs a lot of time and money to ensure its safe efficacy. This is one of the challenges facing the global pharmaceutical industry. Therefore, the development of alternative tools is needed to help in overcoming the prevalence of COVID-19.

Thus, we need to pave the way for unprecedented research efforts and new eligible approaches within a short time. One of the approaches that can play an important role in fighting COVID-19 is "drug repurposing", also called drug repositioning, re-profiling, or re-tasking. Drug repurposing is a strategy of exploring new uses for existing approved drugs that are outside the original medical indication [4]. Therefore, drug repurposing offers a lot of benefits and can be much better than developing an entirely new drug for a certain indication $[5,6]$. Drug repositioning is expanding in the area of rare and neglected diseases. It helps to mitigate failures in drug discovery, and in recent years, approximately one-third of the approvals have been due to drug repurposing. In drug repurposing methods, the hidden therapeutic effects of drugs are investigated using diverse approaches, including computational manners, clinical experiments, and other in vitro approaches. The implementation of data-driven drug repurposing in most cases is integrated with computational assistance $[7,8]$.

Computational approaches are valuable and fundamental tools in drug discovery steps and the development trajectory. Several computational approaches help researchers in the discovery of new drug candidates. An example of these in silico techniques is structure-based virtual screening and molecular docking studies [9]. On the other hand, bioinformatics can be used to detect the main key amino acids at nearly the same normal conditions, and, hence, confirming the docking results and druggability will be also easier to handle. Virtual screening can then provide possible drug candidates based on the chemical nature of the drug and its target protein, saving cost and time, and integrating intellectual intervention [10].

As mentioned earlier, one of the most critical COVID-19 symptoms is the inflammatory cytokine storm. This storm results from lung cells damaged by the virus. Subsequently, a local immune response is triggered, recruiting monocytes and macrophages that release cytokines and prime adaptive T and B cell immune responses [11]. This process is capable of resolving viral infection. In some cases, however, a dysfunctional immune response occurs, which can cause severe lung and even systemic pathology. Thus, the use of antiinflammatory drugs in the COVID-19 treatment protocol is required [11,12]. Moreover, it was also found that SARS-CoV-2 gene mutation may correlate with enhanced cytokine production, such as TNF- $\alpha$ and IL-6 (Figure 1), compared to that isolated from the Wuhan virus, increasing the need for anti-inflammatory drugs [13].

As they are commonly used for pain relief and inflammation cure, non-steroidal anti-inflammatory drugs (NSAIDs) can be considered as an important step in the treatment of COVID-19. Furthermore, indomethacin showed potent antiviral activity against canine coronavirus in vitro, and this activity was also observed in vivo and against human SARS$\mathrm{CoV}$ [14]. Moreover, it was found that rotavirus infectivity was decreased after treatment with NSAIDs (e.g., indomethacin, ibuprofen, mefenamic acid, and ketoprofen) [15]. Besides, auranofin (Gold NSAID) showed the potential to reduce the viral reservoir of HIV (human immunodeficiency virus) in infected T-cells [16].

In vitro studies on NSAIDs revealed that some of them can partially reduce SARS$\mathrm{CoV}-2$ replication. For example, celecoxib, indomethacin, ibuprofen, ketoprofen, ketorolac, meloxicam, and piroxicam were evaluated against NRC-03-nhCoV. The aforementioned drugs exhibited promising antiviral activities with high selectivity indexes relative to cellular toxicity. Piroxicam and indomethacin exhibited the highest potency against NRC03-nhCoV as their $\mathrm{IC}_{50}$ values were estimated at 8.21 and $8.51 \mu \mathrm{M}$, respectively [17]. 


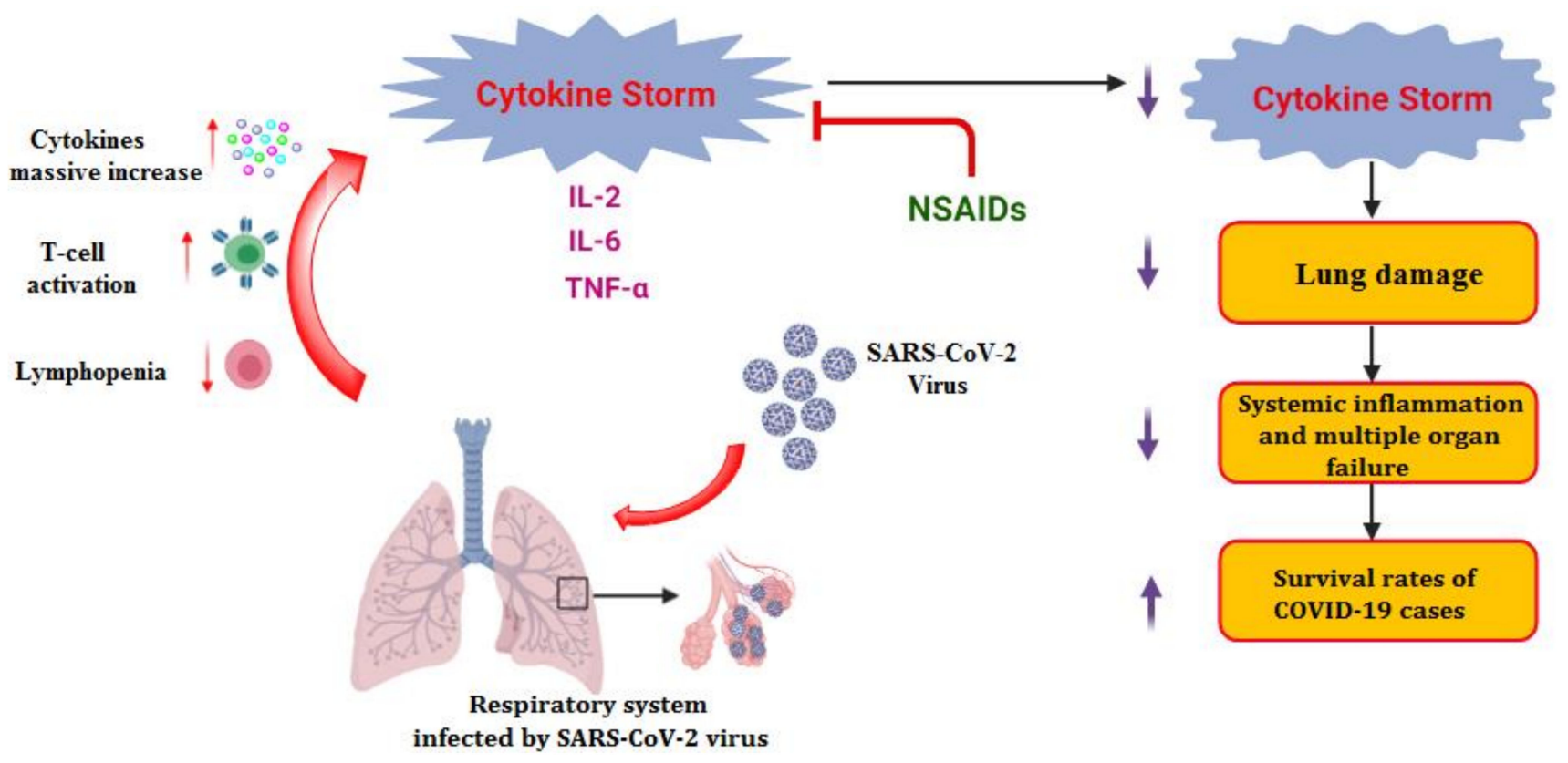

Figure 1. Inflammatory cytokine storm induced by SARS-CoV-2 infections and the role of anti-inflammatory drugs such as NSAIDs.

Therefore, in continuation of our previous work targeting SARS-CoV-2 main protease $[6,18-25]$ as a promising anti-SARS-CoV-2 drug target, and taking into consideration the crucial role of $\mathrm{M}^{\text {pro }}$ enzyme for SARS-CoV-2 replication (the main protease enzyme of SARS-CoV-2 and also known as 3 C-like protease (3CL ${ }^{\text {pro }}$ ), which is responsible for the cleavage of the coronavirus polyprotein at 11 specific sites), besides the previously mentioned activity of some NSAIDs towards different viruses, our perspective in this article is targeting the $\mathrm{M}^{\text {pro }}$ enzyme through virtual screening of a small library of a subset of the approved NSAIDs (Figure 2) via molecular docking of the ligands on the 3D crystal structure of $\mathrm{M}^{\text {pro }}$ (PDB ID: 6LU7) [26]. Thus, we can investigate the best ligands that might have antiviral activity against SARS-CoV-2 or at least recommend the best NSAID members and prioritize them to be used in the treatment of the inflammatory cytokine storms accompanying some COVID-19 cases. Also, our study sheds light on some NSAID candidates as lead compounds that can be optimized in the future to be more effective against SARS-CoV-2, which was accomplished through a structure-activity relationship (SAR) study based on the obtained results.

Molecular dynamics (MD) simulations were carried out on the docked complexes of the highest-ranked docking compounds (sulfinpyrazone 2, indomethacin 3 , and auranofin 4) to gain a deep understanding of the affinity between the ligand and the SARS-CoV-2 main protease active site in the explicit solvent model in order to estimate the stability of the drug within the active site of the protein and consequently confirm the docking results.

Furthermore, sulfinpyrazone and indomethacin have been extensively studied previously for their physicochemical properties [27-29]. On the other hand, auranofin (AF) contains thiosugar moiety in addition to gold $(\mathrm{Au})$, sulfur $(\mathrm{S})$, and phosphorous $(\mathrm{P})$ atoms. Hence, studying the spatial and geometrical properties of AF demands a careful choice of a quantum mechanical method that can describe AF properties more accurately than other methods. Therefore, we herein conduct a comparative study on quantum mechanical methods used to calculate the physicochemical properties of AF. 

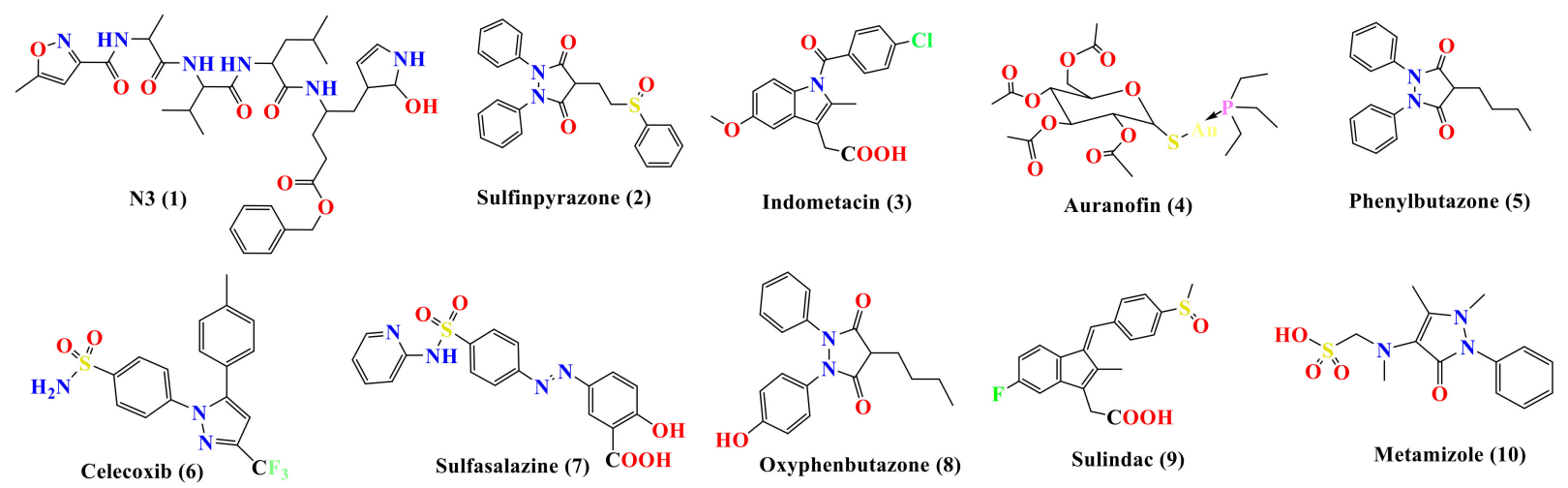

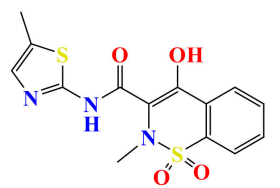

Meloxicam (11)<smiles>O=C(O)CCc1nc(-c2ccccc2)c(-c2ccccc2)o1</smiles>

Oxaprozin (12)

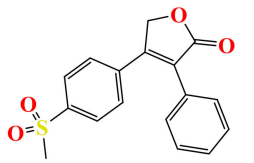

Rofecoxib (17)<smiles>CC(C(=O)O)c1cccc(C(=O)c2ccccc2)c1</smiles>

Ketoprofen (21)<smiles>CC(=O)C(C)C1CCC(CC(C)C)CC1</smiles>

Ibuprofen (26)<smiles>C=C(Nc1cccc(C(=O)O)c1)C1CCC(C(F)(F)F)C1</smiles><smiles>Cc1ccc(C(=O)c2ccc(CC(=O)O)n2C)cc1</smiles>

Tolmetin (22)<smiles>CC(=O)C(C)c1cccc(Oc2ccccc2)c1</smiles>

Fenoprofen (27)<smiles>Cc1cccc(Nc2ccccc2C(=O)O)c1C</smiles>

Mefenamic acid (32)
O

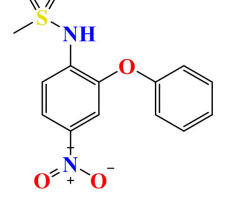

Nimesulide (13)

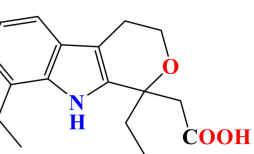

Etodolac (18)

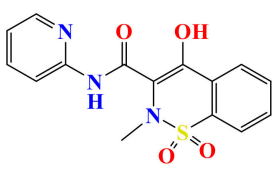

Piroxicam (14)

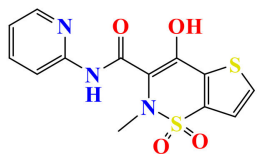

Tenoxicam (19)
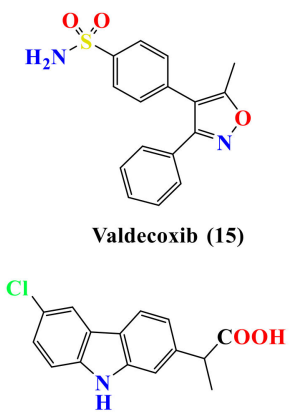

Carprofen (20)<smiles>COc1ccc2cc(CCC(C)=O)ccc2c1</smiles><smiles>CCCC[As]([O])(CCC)C1CCC(CC)CC1</smiles>

Probenecid (24)

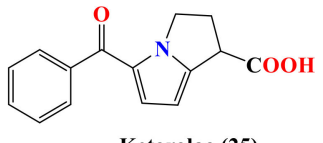

Ketorolac (25)<smiles>CC(C(=O)O)c1ccc(-c2ccccc2)c(F)c1</smiles>

Flurbiprofen (28)<smiles>O=C(Oc1ccccc1COCCO)C1CCCCC1</smiles>

Salsalate (29)<smiles>COc1ccc2cc(C(C)C(=O)O)ccc2c1</smiles>

Naproxen (30)<smiles>O=C(O)Cc1ccccc1Nc1c(Cl)cccc1Cl</smiles><smiles>Cc1ccc(Cl)c(Nc2ccccc2C(=O)O)c1Cl</smiles><smiles>CCOc1ccc(NC(C)=O)cc1</smiles>

Diclofenac (33)<smiles>CC(=O)Oc1ccccc1C(=O)O</smiles>

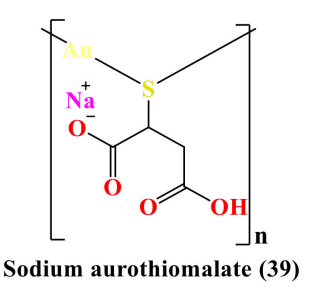<smiles>CC(=O)Nc1ccc(O)cc1</smiles><smiles>O=c1ncnc2[nH][nH]cc1-2</smiles>

Allopurinol (41)

Figure 2. Chemical structures (in descending order of their docking scores): N3 1, Sulfinpyrazone 2, Indomethacin 3 , Auranofin 4, Phenylbutazone 5, Celecoxib 6, sulfasalazine 7, Oxyphenbutazone 8, Sulindac 9, Metamizole 10, Meloxicam 11, Oxaprozin 12, Nimesulide 13, Piroxicam 14, Valdecoxib 15, Zomepirac 16, Rofecoxib 17, Etodolac 18, Tenoxicam 19, Carprofen 20, Ketoprofen 21, Tolmetin 22, Nabumetone 23, Probenecid 24, Ketorolac 25, Ibuprofen 26, Fenoprofen 27, Flurbiprofen 28, Salsalate 29, Naproxen 30, Flufenamic acid 31, Mefenamic acid 32, Diclofenac 33, Meclofenamic acid 34, Phenacetin 35, Diflunisal 36, Aurothioglucose 37, Aspirin 38, Sodium aurothiomalate 39, Paracetamol 40, and Allopurinol 41. 


\section{Materials and Methods}

Docking studies using MOE 2019 suite [30] and molecular dynamics simulation studies using the Desmond simulation package of Schrödinger LLC [31] were carried out to examine and confirm the binding affinities and modes of the 40 selected FDA-approved NSAIDs against the viral main protease of SARS-CoV-2. The co-crystallized inhibitor (N3) was used as a reference standard.

\subsection{Molecular Docking}

\subsubsection{NSAIDs Preparation}

The tested compounds were downloaded from (https:/ / pubchem.ncbi.nlm.nih.gov / last accessed on 1 April 2021) website. Their structures and the formal charges on atoms were checked by the 2D depiction, subjected to energy minimization, and the partial charges were automatically calculated. The tested compounds together with the co-crystallized ligand (N3 inhibitor) were imported into the same database and saved in the form of an MDB file for the docking calculations with the target protease.

\subsubsection{Target (SARS-CoV-2 Mpro) Preparation}

Protein Data Bank was used to download the crystal structure of SARS-CoV-2 main protease (M $\mathrm{M}^{\mathrm{pro}}$ ) (PDB code 6LU7, resolution: $2.16 \AA$ ) [26]. The downloaded protein was prepared as previously described [32]. Briefly, it was protonated and hydrogen atoms were added with their standard 3D geometry. Automatic correction for any errors in the atom's connection and the type was also applied. Site Finder was applied for selection of the same active site of the co-crystallized inhibitor using all default parameters, and dummy atoms of the pocket were then created.

\subsubsection{Docking of the Tested NSAIDs to the Viral Mpro Binding Site}

Docking of the previously prepared database composed of our tested 40 NSAIDs and the co-crystallized inhibitor N3 was performed. The general methodology was applied as described earlier where the placement methodology was specified as triangle matcher and the scoring methodology was selected as London dG. Moreover, the refinement methodology was applied as a rigid receptor and the scoring methodology was GBVI/WSA [33,34]. Briefly, the file of the prepared active site was loaded and the general docking process was initiated. The obtained poses were studied after completion and the ones having the best ligand-enzyme interactions and the most acceptable Root Mean Squared Deviation (RMSD_refine) values were selected and stored for energy calculations. In the beginning, a validation process was also performed for the target receptor by docking only the co-crystallized ligand, and low RMSD values between the docked and the crystal conformations indicated a valid performance $[35,36]$.

\subsection{Molecular Dynamics (MD) Simulations}

The Schrödinger LLC package [31] was used to carry out the MD simulations. The simulation system was immersed in an orthorhombic box with edges at $10 \AA$ away from the protein molecule, implementing periodic boundary conditions. The box was filled with water described by the TIP3P model $[37,38]$. Salt concentration was set to $0.15 \mathrm{M} \mathrm{NaCl}$ using the Desmond system builder [39]. The OPLS3 force field [40] was utilized for the protein and the ligand parameters. The MD simulations were performed for $150 \mathrm{~ns}$ at the NPT ensemble (constant number of particles, pressure, and temperature). The pressure was kept constant at $1 \mathrm{~atm}$ implementing the Martyna-Tuckerman-Klein chain coupling scheme with $2.0 \mathrm{ps}$ as coupling constant. The temperature was controlled at $300 \mathrm{~K}$ using the Nosé-Hoover chain coupling scheme $[41,42]$. Coulombic interactions were calculated using a cut-off radius of $0.9 \AA$. 


\subsection{Quantum Mechanical Studies}

All calculations were performed on the Swinburne supercomputer using GAUSSIAN 09 Revision C.01 [43]. Four hybrid functionals B3PW91 [44], CAM-B3LYP [45], PBE1PBE [46], and wB97X [47] were utilized in conjunction with the split valence and triple zeta basis set def2tzv [48,49] for the description of the gold $(\mathrm{Au})$ atom, and the standard basis set 6-311G [50] for the description of all other atoms in the auranofin (AF) molecule. Energy optimization of AF was performed in three consecutive steps utilizing 6-311G, $6-311+G^{*}$, and $6-311++G^{* *}$ for the description of all atoms except Au. Frequency calculation for geometries obtained from each function was then performed and no imaginary frequency was detected. The electronic circular dichroism of the AF excited state was then computed using the Density-Functional Theory (td-DFT) method.

\section{Results and Discussion}

\subsection{Docking Studies}

The SARS-CoV-2 Mpro has a Cys-His catalytic dyad, and the inhibitor-binding site is present in a groove between domains I and II. The N3 inhibitor is fitted inside the substrate-binding pocket of SARS-CoV-2 $\mathrm{M}^{\text {pro }}$ showing asymmetric units containing only one polypeptide. Molecular docking simulation of N3 inhibitor 1 and the FDA-approved NSAIDs (2-41) - described in Figure 2-into $\mathrm{M}^{\text {pro }}$ active site was done. They were stabilized at the N3-binding site of $\mathrm{M}^{\text {pro }}$ by variable several electrostatic interactions (Table 1). The order of binding strength was: N3 inhibitor $(\mathbf{1}$, docked) $>$ sulfinpyrazone $\mathbf{2}>$ indomethacin 3 $>$ auranofin $4>$ phenylbutazone $5>$ celecoxib $6>$ sulfasalazine $7>$ oxyphenbutazone $8>$ sulindac $9>$ metamizole $10>$ meloxicam $11>$ oxaprozin $12>$ nimesulide $13>$ piroxicam 14 $>$ valdecoxib $15>$ zomepirac $16>$ rofecoxib $17>$ etodolac $18>$ tenoxicam $19>$ carprofen $20>$ ketoprofen $21>$ tolmetin $22>$ nabumetone $23>$ probenecid $\mathbf{2 4}>$ ketorolac $25>$ ibuprofen 26 $>$ fenoprofen $27>$ flurbiprofen $\mathbf{2 8}>$ salsalate $29>$ naproxen $\mathbf{3 0}>$ flufenamic acid $\mathbf{3 1}>$ mefenamic acid $32>$ diclofenac $33>$ meclofenamic acid $34>$ phenacetin $35>$ diflunisal $36>$ aurothioglucose $37>$ aspirin $38>$ sodium aurothiomalate $39>$ paracetamol $40>$ allopurinol 41.

Many poses were obtained with better binding modes and interactions inside the receptor pocket. The poses binding to the main amino acids with the best scores and RMSD_refine values were selected. Results of scores, RMSD values, and different interactions with amino acids of the $\mathrm{M}^{\text {pro }}$ pocket are represented in Table 1.

The results of docking studies revealed that sulfinpyrazone 2 , indomethacin 3 , and auranofin 4 had the best binding affinities and modes against SARS-CoV-2 main protease with binding free energies of $-7.12,-7.07$, and $-6.91 \mathrm{kcal} / \mathrm{mol}$, respectively (Table 1 ). These energy values were near to that of the docked N3 inhibitor (binding energy = $-9.39 \mathrm{kcal} / \mathrm{mol}$ ), and concerning that the catalytic dyad of SARS-CoV-2 Mpro is composed of cysteine and histidine amino acids.

The detailed binding mode of N3 was as follows; the docked N3 moiety occupied the branched pocket of $\mathrm{M}^{\text {pro }}$, forming four hydrogen bonds with Glu166, Gln189, Ser46, and Met49 at 2.94, 3.05, 3.12, and $3.51 \AA$, respectively. It also formed one pi-H interaction with His41 at $4.19 \AA$ A. However, sulfinpyrazone 2 formed two H-bonds with Glu166 and His41 at 2.98 and $3.21 \AA$, respectively, and a pi-H interaction with Gly143 at $3.58 \AA$. Furthermore, indomethacin 3 showed the formation of three hydrogen bonds, one with His163 at $3.49 \AA$ and two with Met165 at 3.89 and 4.11 . It also formed one H-pi interaction with His41 and another pi-H interaction with Glu166 at 3.87 and $4.30 \AA$, respectively. On the other hand, auranofin 4 formed five hydrogen bonds with His41, His163, Leu141, Asn142, and Gln189 at 2.90, 3.10, 3.39, 3.41, and $3.49 \AA$, respectively, and an H-pi interaction with His41 at $4.20 \AA$ (Table 2). 
Table 1. Receptor interactions and binding energies of the identified NSAIDs and N3 inhibitor (docked) into the N3 binding site of SARS-CoV-2 main protease.

\begin{tabular}{|c|c|c|c|c|c|}
\hline No. & NSAID & $\mathrm{S}^{\text {a }} \mathrm{kcal} / \mathrm{mol}$ & RMSD_Refine ${ }^{b}$ & Amino Acid Bond & Distance Å \\
\hline 1 & N3 & -9.39 & 1.78 & $\begin{array}{c}\text { Glu166/H-donor } \\
\text { Gln189/H-acceptor } \\
\text { Ser46/H-acceptor } \\
\text { Met49/H-acceptor } \\
\text { His41/pi-H }\end{array}$ & $\begin{array}{l}2.94 \\
3.05 \\
3.12 \\
3.51 \\
4.19\end{array}$ \\
\hline 2 & Sulfinpyrazone & -7.12 & 1.66 & $\begin{array}{l}\text { Glu166/H-donor } \\
\text { His41/H-donor } \\
\text { Gly143/H-pi }\end{array}$ & $\begin{array}{l}2.98 \\
3.21 \\
3.58\end{array}$ \\
\hline 3 & Indomethacin & -7.07 & 1.51 & $\begin{array}{c}\text { His163/H-donor } \\
\text { Met165/H-acceptor } \\
\text { Met165/H-acceptor } \\
\text { His41/pi-H } \\
\text { Glu166/H-pi }\end{array}$ & $\begin{array}{l}3.49 \\
3.89 \\
4.11 \\
3.87 \\
4.30\end{array}$ \\
\hline 4 & Auranofin & -6.91 & 0.84 & $\begin{array}{l}\text { His41/H-donor } \\
\text { His163/H-donor } \\
\text { Leu141/H-acceptor } \\
\text { Asn142/H-donor } \\
\text { Gln189/H-donor } \\
\text { His41/pi-H }\end{array}$ & $\begin{array}{l}2.90 \\
3.10 \\
3.39 \\
3.41 \\
3.49 \\
4.20\end{array}$ \\
\hline 5 & Phenylbutazone & -6.88 & 1.07 & Glu166/H-donor & 3.43 \\
\hline 6 & Celecoxib & -6.79 & 1.17 & $\begin{array}{c}\text { Ser144/H-donor } \\
\text { His163/H-donor } \\
\text { Asn142/H-acceptor } \\
\text { Gln189/H-pi }\end{array}$ & $\begin{array}{l}3.01 \\
3.04 \\
3.88 \\
4.38\end{array}$ \\
\hline 7 & Sulfasalazine & -6.76 & 1.77 & $\begin{array}{c}\text { Thr190/H-acceptor } \\
\text { Glu166/H-acceptor } \\
\text { Gly143/H-donor } \\
\text { His41/H-donor }\end{array}$ & $\begin{array}{l}2.82 \\
3.03 \\
3.14 \\
3.16\end{array}$ \\
\hline 8 & Oxyphenbutazone & -6.75 & 2.00 & $\begin{array}{c}\text { His164/H-acceptor } \\
\text { Asn142/H-donor } \\
\text { Gly143/H-donor }\end{array}$ & $\begin{array}{l}3.12 \\
3.47 \\
3.56\end{array}$ \\
\hline 9 & Sulindac & -6.67 & 1.25 & $\begin{array}{l}\text { Gly143/H-donor } \\
\text { Cys145/H-donor } \\
\text { Glu166/H-pi }\end{array}$ & $\begin{array}{l}2.99 \\
3.14 \\
4.49\end{array}$ \\
\hline 10 & Metamizole & -6.56 & 1.49 & $\begin{array}{l}\text { Gln189/H-acceptor } \\
\text { Met165/H-acceptor } \\
\text { Met165/H-acceptor } \\
\text { Met165/H-pi } \\
\text { His41/pi-H } \\
\text { Glu166/H-pi }\end{array}$ & $\begin{array}{l}3.49 \\
3.55 \\
3.85 \\
3.50 \\
4.18 \\
4.24\end{array}$ \\
\hline 11 & Meloxicam & -6.47 & 1.35 & $\begin{array}{l}\text { His163/H-donor } \\
\text { His164/H-acceptor } \\
\text { His164/H-acceptor }\end{array}$ & $\begin{array}{l}2.84 \\
3.15 \\
3.28\end{array}$ \\
\hline 12 & Oxaprozin & -6.43 & 1.20 & $\begin{array}{c}\text { Ser144/H-donor } \\
\text { Glu166/H-pi } \\
\text { Gln189/H-pi }\end{array}$ & $\begin{array}{l}2.97 \\
3.83 \\
4.03\end{array}$ \\
\hline 13 & Nimesulide & -6.35 & 1.35 & $\begin{array}{l}\text { His41/H-donor } \\
\text { His163/H-donor } \\
\text { Cys145/H-donor }\end{array}$ & $\begin{array}{l}2.86 \\
2.91 \\
3.46\end{array}$ \\
\hline
\end{tabular}


Table 1. Cont.

\begin{tabular}{|c|c|c|c|c|c|}
\hline No. & NSAID & $\mathrm{S}^{\mathrm{a}} \mathrm{kcal} / \mathrm{mol}$ & RMSD_Refine ${ }^{b}$ & Amino Acid Bond & Distance Å \\
\hline 14 & Piroxicam & -6.30 & 1.32 & $\begin{array}{c}\text { His41/H-donor } \\
\text { Cys145/H-acceptor } \\
\text { Met165/H-pi } \\
\text { His41/pi-H } \\
\text { Glu166/H-pi }\end{array}$ & $\begin{array}{l}3.30 \\
3.81 \\
3.46 \\
3.54 \\
4.54 \\
\end{array}$ \\
\hline 15 & Valdecoxib & -6.30 & 1.12 & $\begin{array}{l}\text { Glu166/H-acceptor } \\
\text { Met165/H-acceptor } \\
\text { Gln189/H-donor }\end{array}$ & $\begin{array}{l}2.89 \\
3.40 \\
3.41 \\
\end{array}$ \\
\hline 16 & Zomepirac & -6.25 & 1.40 & $\begin{array}{l}\text { His163/H-donor } \\
\text { Met165/H-pi }\end{array}$ & $\begin{array}{l}3.14 \\
4.42\end{array}$ \\
\hline 17 & Rofecoxib & -6.24 & 1.02 & $\begin{array}{c}\text { Cys145/H-donor } \\
\text { Met165/H-acceptor } \\
\text { Asn142/H-pi }\end{array}$ & $\begin{array}{l}2.99 \\
3.48 \\
4.15\end{array}$ \\
\hline 18 & Etodolac & -6.19 & 0.68 & $\begin{array}{l}\text { Arg188/H-donor } \\
\text { Glu166/H-pi }\end{array}$ & $\begin{array}{l}3.28 \\
3.74\end{array}$ \\
\hline 19 & Tenoxicam & -6.18 & 1.47 & $\begin{array}{l}\text { Gly143/H-donor } \\
\text { His164/H-acceptor } \\
\text { Asn142/H-donor } \\
\text { Gly143/H-donor }\end{array}$ & $\begin{array}{l}2.92 \\
3.14 \\
3.18 \\
3.29\end{array}$ \\
\hline 20 & Carprofen & -6.15 & 0.90 & $\begin{array}{c}\text { His164/H-acceptor } \\
\text { Gln192/H-acceptor } \\
\text { Gln189/H-pi }\end{array}$ & $\begin{array}{l}2.95 \\
3.77 \\
4.53\end{array}$ \\
\hline 21 & Ketoprofen & -6.15 & 1.57 & Glu166/H-donor & 2.99 \\
\hline 22 & Tolmetin & -6.08 & 1.64 & $\begin{array}{l}\text { Gly143/H-donor } \\
\text { His164/H-acceptor } \\
\text { Cys145/H-donor } \\
\text { Met49/H-acceptor }\end{array}$ & $\begin{array}{l}3.01 \\
3.08 \\
3.36 \\
3.93\end{array}$ \\
\hline 23 & Nabumetone & -6.02 & 1.14 & $\begin{array}{l}\text { His163/H-donor } \\
\text { Met165/H-pi } \\
\text { Glu166/H-pi }\end{array}$ & $\begin{array}{l}3.16 \\
3.74 \\
4.16 \\
\end{array}$ \\
\hline 24 & Probenecid & -5.96 & 2.19 & $\begin{array}{l}\text { Glu166/H-donor } \\
\text { Gln189/H-acceptor }\end{array}$ & $\begin{array}{l}3.17 \\
3.44\end{array}$ \\
\hline 25 & Ketorolac & -5.89 & 1.57 & $\begin{array}{l}\text { Glu166/H-donor } \\
\text { Glu166/H-acceptor }\end{array}$ & $\begin{array}{l}3.05 \\
3.27\end{array}$ \\
\hline 26 & Ibuprofen & -5.88 & 0.87 & $\begin{array}{l}\text { Leu141/H-acceptor } \\
\text { His163/H-donor }\end{array}$ & $\begin{array}{l}2.99 \\
3.03\end{array}$ \\
\hline 27 & Fenoprofen & -5.84 & 1.14 & $\begin{array}{l}\text { His163/H-donor } \\
\text { His163/H-donor } \\
\text { Glu166/H-pi } \\
\text { Met165/H-pi }\end{array}$ & $\begin{array}{l}3.01 \\
3.14 \\
4.04 \\
4.22\end{array}$ \\
\hline 28 & Flurbiprofen & -5.74 & 1.03 & $\begin{array}{c}\text { Phe140/H-acceptor } \\
\text { His163/H-donor } \\
\text { Asn142/H-pi }\end{array}$ & $\begin{array}{l}2.91 \\
3.08 \\
3.82 \\
\end{array}$ \\
\hline 29 & Salsalate & -5.72 & 1.78 & $\begin{array}{c}\text { Gln189/H-acceptor } \\
\text { Glu166/H-donor His41/pi-H }\end{array}$ & $\begin{array}{l}3.08 \\
3.17 \\
3.90\end{array}$ \\
\hline 30 & Naproxen & -5.72 & 1.61 & $\begin{array}{l}\text { Gly143/H-donor } \\
\text { Cys145/H-donor }\end{array}$ & $\begin{array}{l}3.08 \\
3.31\end{array}$ \\
\hline
\end{tabular}


Table 1. Cont.

\begin{tabular}{|c|c|c|c|c|c|}
\hline No. & NSAID & $\mathrm{S}^{\mathrm{a}} \mathrm{kcal} / \mathrm{mol}$ & RMSD_Refine $^{b}$ & Amino Acid Bond & Distance $\AA$ \\
\hline 31 & Flufenamic acid & -5.70 & 1.26 & $\begin{array}{l}\text { His164/H-acceptor } \\
\text { Ser144/H-donor } \\
\text { Ser144/H-donor } \\
\text { His164/H-acceptor } \\
\text { Cys145/H-acceptor }\end{array}$ & $\begin{array}{l}2.95 \\
2.98 \\
3.09 \\
3.13 \\
3.21\end{array}$ \\
\hline 32 & Mefenamic acid & -5.68 & 2.08 & $\begin{array}{c}\text { Glu166/H-donor } \\
\text { Gln189/H-acceptor } \\
\text { Met165/H-acceptor } \\
\text { Gln189/H-pi }\end{array}$ & $\begin{array}{l}3.06 \\
3.21 \\
3.68 \\
4.05\end{array}$ \\
\hline 33 & Diclofenac & -5.54 & 1.66 & $\begin{array}{l}\text { Gln189/H-acceptor } \\
\text { Glu166/H-donor } \\
\text { Gly143/H-donor } \\
\text { Leu141/H-acceptor }\end{array}$ & $\begin{array}{l}2.89 \\
2.94 \\
3.25 \\
3.73\end{array}$ \\
\hline 34 & Meclofenamic acid & -5.48 & 1.18 & $\begin{array}{l}\text { Glu166/H-acceptor } \\
\text { Gln192/H-donor } \\
\text { Glu166/H-acceptor }\end{array}$ & $\begin{array}{l}2.84 \\
3.09 \\
3.17\end{array}$ \\
\hline 35 & Phenacetin & -5.43 & 1.27 & $\begin{array}{c}\text { Glu166/H-acceptor } \\
\text { Gln189/H-donor } \\
\text { His41/pi-H }\end{array}$ & $\begin{array}{l}3.03 \\
3.37 \\
4.18\end{array}$ \\
\hline 36 & Diflunisal & -5.26 & 1.52 & $\begin{array}{c}\text { Leu141/H-acceptor } \\
\text { His163/H-donor } \\
\text { His41/pi-H }\end{array}$ & $\begin{array}{l}2.80 \\
2.97 \\
3.83\end{array}$ \\
\hline 37 & Aurothioglucose & -4.90 & 1.45 & $\begin{array}{l}\text { His163/H-donor } \\
\text { Glu166/H-acceptor } \\
\text { Glu166/H-donor } \\
\text { Met165/H-donor }\end{array}$ & $\begin{array}{l}3.17 \\
3.22 \\
3.76 \\
4.08\end{array}$ \\
\hline 38 & Aspirin & -4.81 & 1.31 & $\begin{array}{l}\text { Gln189/H-acceptor } \\
\text { Glu 166/H-donor }\end{array}$ & $\begin{array}{l}2.82 \\
3.53\end{array}$ \\
\hline 39 & Sodium aurothiomalate & -4.67 & 1.42 & $\begin{array}{c}\text { His164/H-acceptor } \\
\text { Arg188/H-donor } \\
\text { Met49/H-acceptor }\end{array}$ & $\begin{array}{l}2.83 \\
3.55 \\
3.87\end{array}$ \\
\hline 40 & Paracetamol & -4.53 & 0.44 & $\begin{array}{c}\text { Glu166/H-acceptor } \\
\text { Glu166/H-pi }\end{array}$ & $\begin{array}{l}3.11 \\
4.25\end{array}$ \\
\hline 41 & Allopurinol & -4.33 & 1.13 & $\begin{array}{l}\text { Asp187/H-acceptor } \\
\text { Gln189/H-pi }\end{array}$ & $\begin{array}{l}3.24 \\
3.52\end{array}$ \\
\hline
\end{tabular}

a S: Score of a compound into the binding pocket of the receptor, ${ }^{\mathbf{b}}$ RMSD_Refine: Root Mean Squared-Deviation between the predicted pose (after refinement) and the crystal structure (before refinement). 
Table 2. The 3D view of binding interactions and the 3D positioning between the tested NSAID drugs and N3-binding pocket within the SARS-CoV-2 main protease compared to the N3 (Docked).

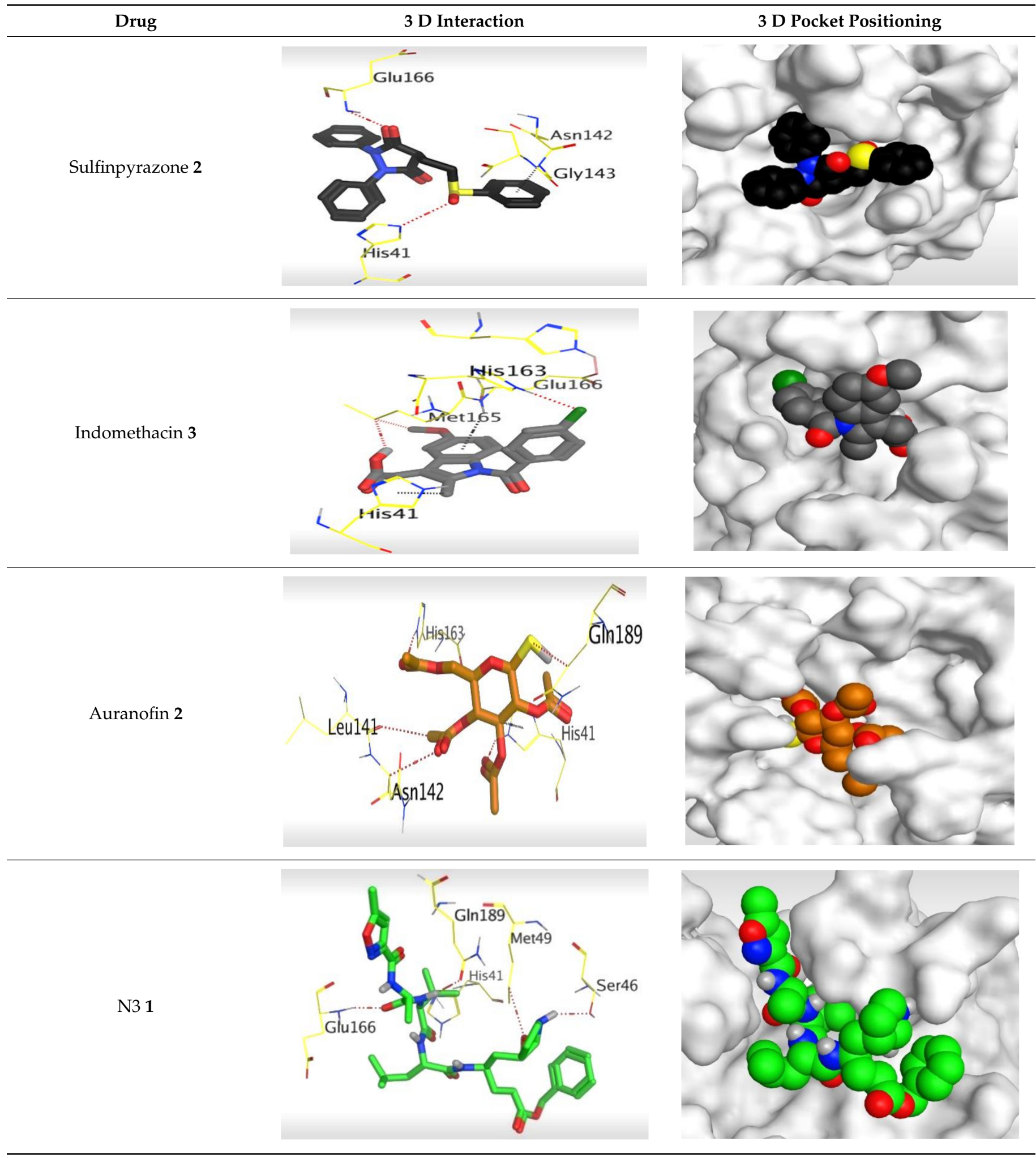

Red dashed lines refer to hydrogen bonds. 


\subsection{Molecular Dynamics (MD) Simulations}

To get a deeper insight into the stability of the best three docked compounds $(2,3$, and 4), molecular dynamics simulations were carried out for $150 \mathrm{~ns}$ simulation time. The co-crystallized peptide ligand $\mathrm{M}^{\text {pro }}$ complex was also subjected to MD simulation to be accounted for as a reference, resulting in a total of four dynamics runs.

Analyses of protein RMSD (Root Mean Square Deviation) and RMSF (Root Mean Square Fluctuation) are depicted in Figure 3. Protein structure stability throughout the simulation time is measured by protein RMSD. RMSD in the four dynamics run shows stability throughout the simulation time as compared to the reference N3 complex run.

(A)

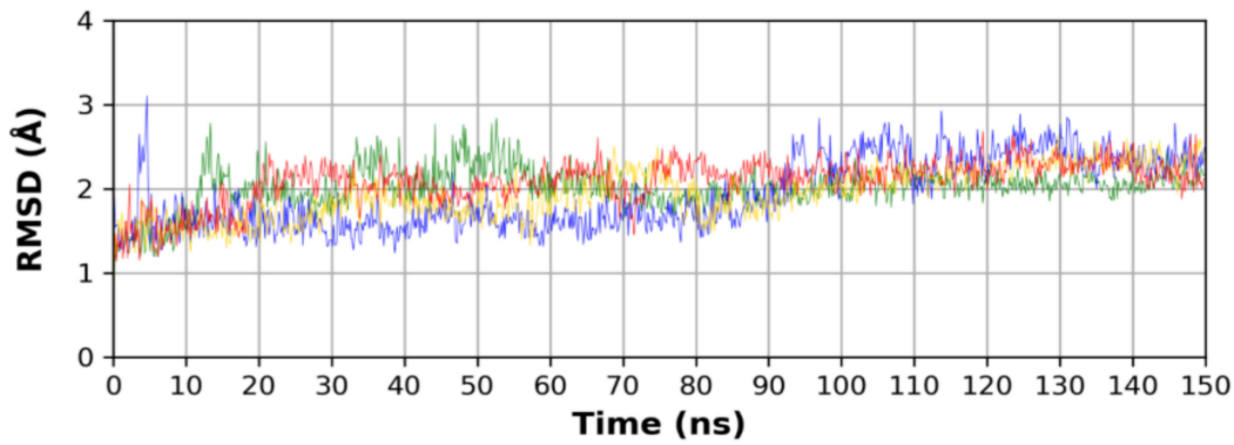

(B)

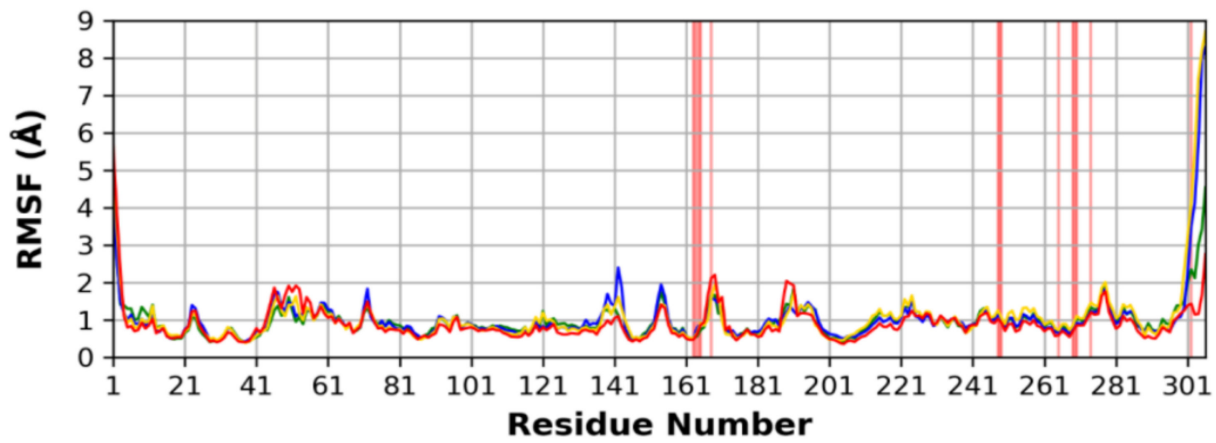

(C)

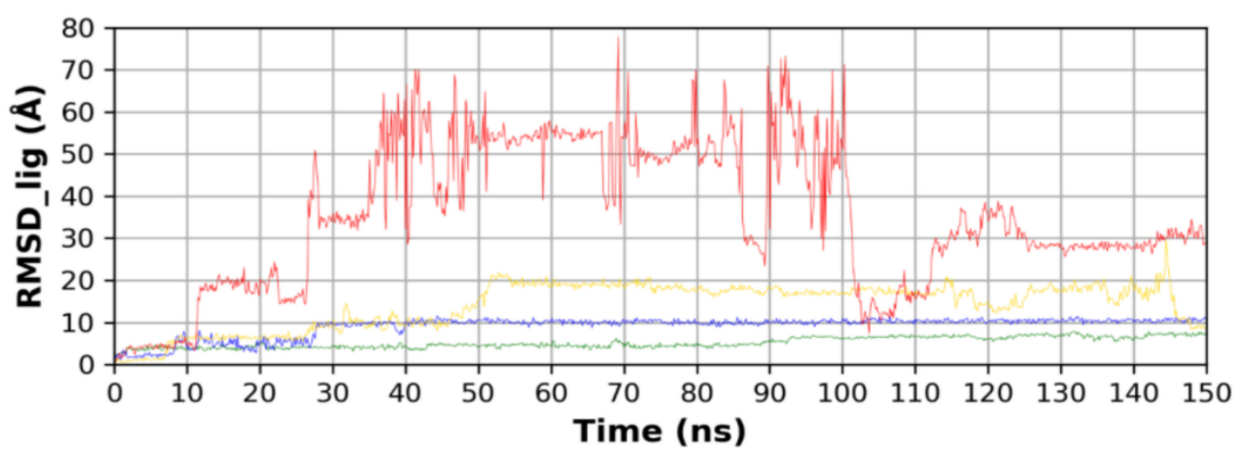

Figure 3. (A) RMSD (Root Mean Square Deviation) of the protein during the simulation time. (B) Per residue RMSF (Root Mean Square Fluctuation) of the protein amino acids. (C) RMSD of the docked poses of the four ligands inside the protein binding site. (Green: N3, Blue: Sulfinpyrazone, Yellow: Indomethacin, Red: Auranofin.)

RMSF is a measure of stability per protein residues and protein local conformational changes during the simulation. Binding site residues showed minimal local conformational changes $(<2 \AA)$ when compared to the reference structure, which indicates the conformational stability of the binding site during the simulation. Both $\mathrm{N}$ - and C-termini showed higher RMSF, which conforms with their high flexibility due to their flexible loop structures.

RMSD analysis of each ligand (RMSD_lig) during the simulation time is depicted in Figure 3. RMSD_lig indicates the stability of the docked pose inside the protein binding site. N3 co-crystallized ligand showed the lowest RMSD, which reflects its strongest binding to the binding site, due to its high anchorage sites to the binding site amino acids. 
Sulfinpyrazone showed the highest stability among the three simulated drugs. This was reflected by its low RMSD_lig and low fluctuations during the simulation time, which indicate the stability of its binding pose. Indomethacin came in third in stability ranking indicated by its slightly higher RMSD_lig than sulfinpyrazone. Additionally, the high fluctuation of RMSD_lig during the simulation was another factor affecting its weaker binding than sulfinpyrazone. Finally, auranofin showed the highest deviation from its initial predicted binding pose, as indicated by its high RMSD_lig during the simulation time. RMSD_lig of auranofin reached $80 \AA$, which indicates that it completely abandoned the protein binding site, also indicated by its high RMSD_lig fluctuation.

Figure 4 shows snapshots of the simulation at 0,75 , and $150 \mathrm{~ns}$. For sulfinpyrazone, it showed stable binding inside the protein binding site, which is indicated by its binding poses at the start, middle, and end of the simulation. Concerning indomethacin, it abandoned the binding site in the middle of the simulation but retrieved a binding pose inside the binding site at the end of the simulation. On the contrary, auranofin abandoned its initial binding pose at the middle of the simulation, which explains its high RMSD_lig, and showed a binding near the binding site at the end of the simulation.

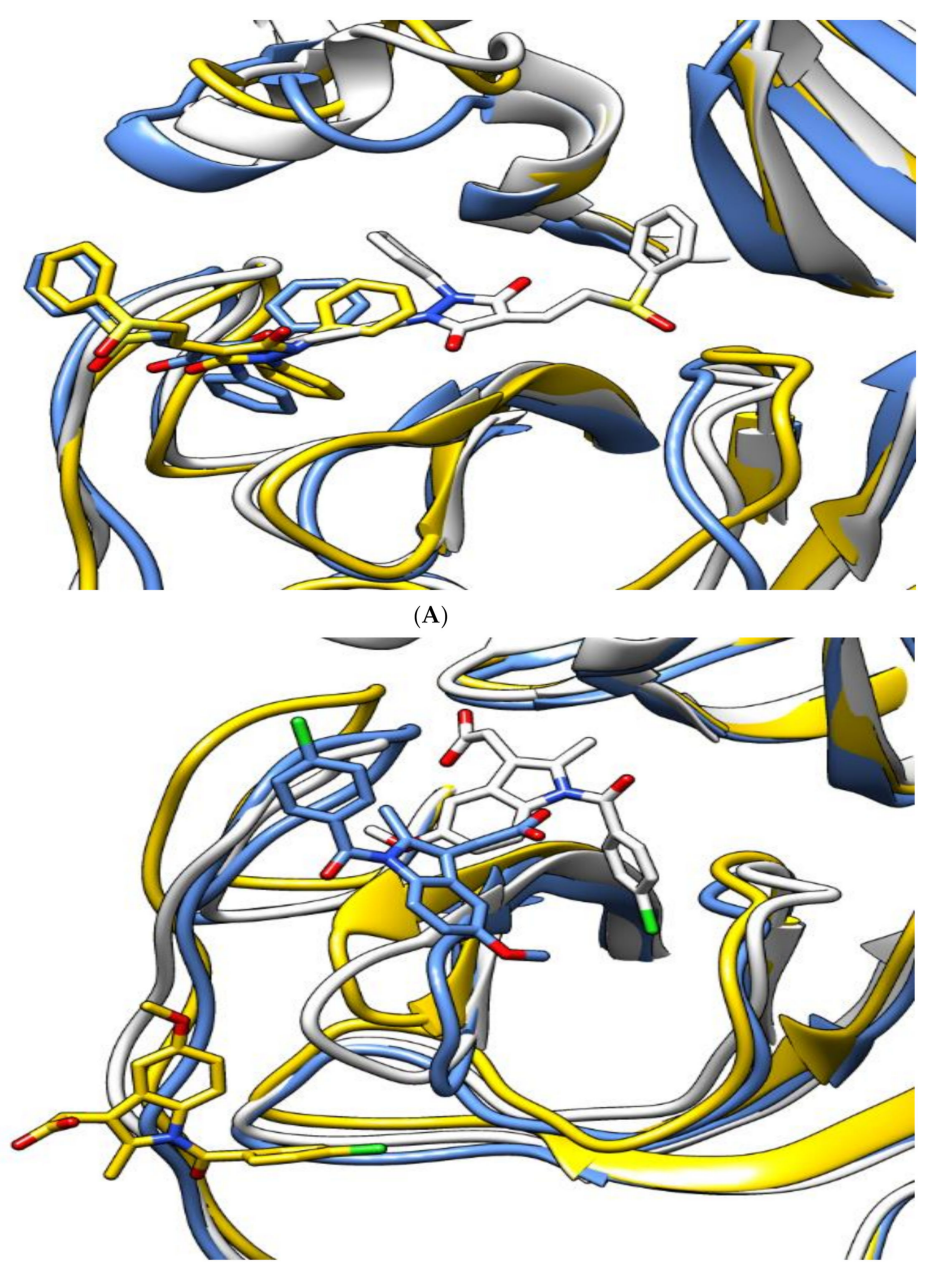

(B)

Figure 4. Cont. 


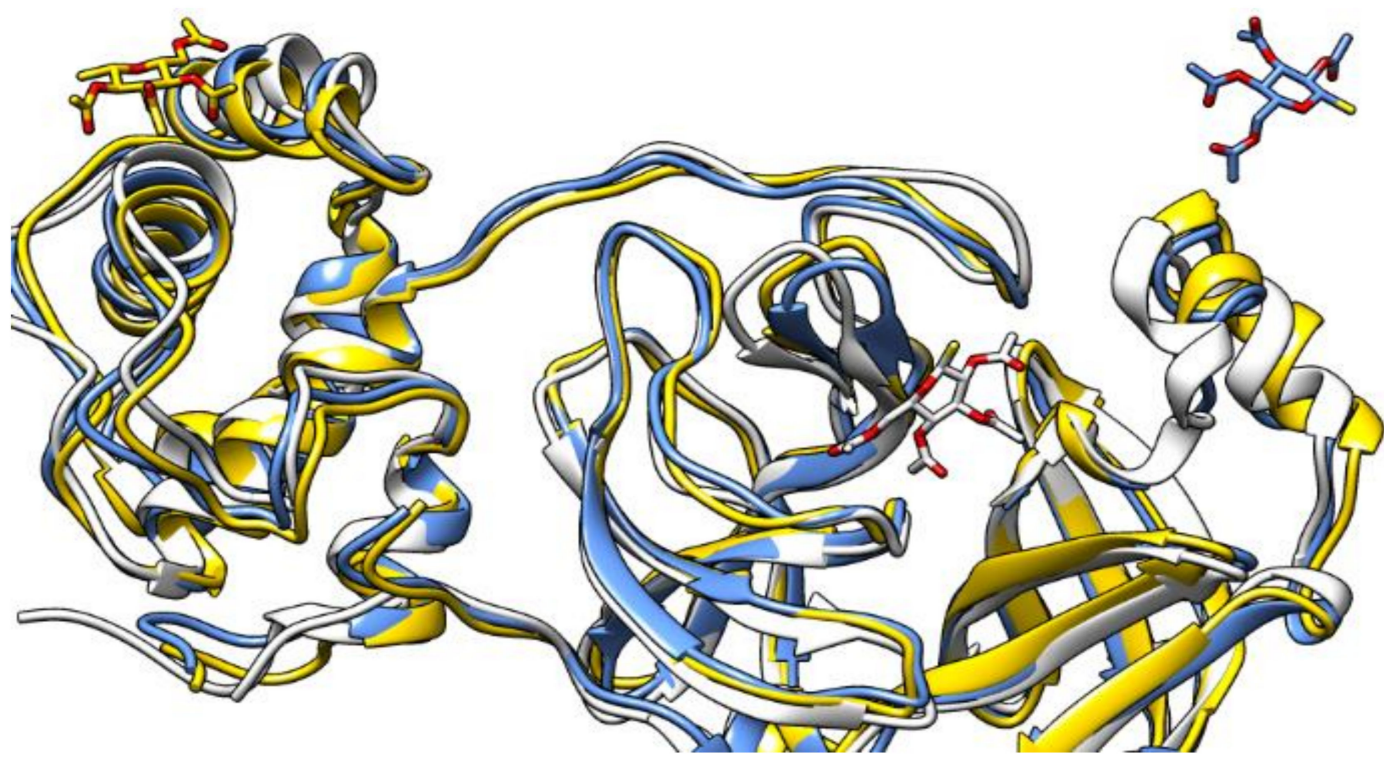

(C)

Figure 4. The aligned structures of protein-ligand complexes for sulfinpyrazone (A), indomethacin (B), and auranofin (C) during simulation. (White: 0 ns, yellow: 75 ns, blue: $150 \mathrm{~ns}$.)

Figure 5 shows the number of hydrogen bonds formed between each ligand and the protein during the simulation time. N3 showed the highest number of hydrogen bonds with the protein due to its higher number of hydrogen bond donor/acceptor anchorage sites with the protein. Sulfinpyrazone showed the highest average number of hydrogen bonds among the three NSAIDs with the protein during the simulation time. Indomethacin and auranofin showed a lower number of hydrogen bonds compared to sulfinpyrazone. Figure 5 also shows the complete absence of hydrogen bonds formed by auranofin during most of the simulation time.
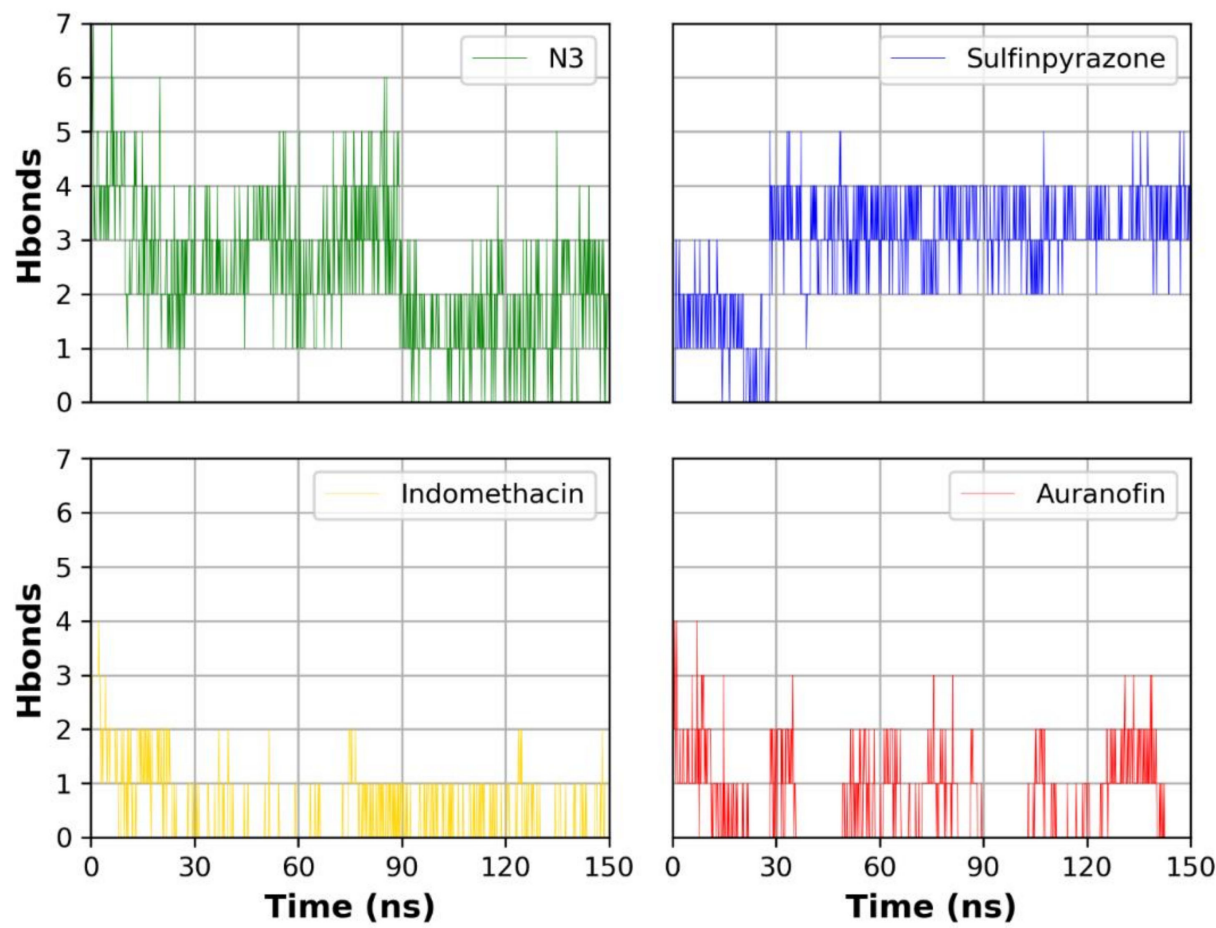

Figure 5. Number of hydrogen bonds formed between each ligand and the protein during the simulation. 
The binding interactions histogram was calculated for each protein-ligand complex during the simulation and is depicted in Figure 6. In the case of sulfinpyrazone, the amino acids (Arg188, Gln189, Thr190, Ala191, and Gln192) had the greatest contribution to the hydrogen bonding interactions with sulfinpyrazone (40-80\%), and His164 contributed mainly with hydrophobic interactions (>80\%). Leu27, Ser46, Met49, Glu166, Leu167, and Ala173 also contributed with $<30 \%$ to the hydrophobic interactions. Figure 7 shows the timeline heat map for the total number of contacts between each ligand and the protein. The main binding residues with sulfinpyrazone were Met165, Gln189, Thr190, Ala191, and Gln192, which maintained contacts with sulfinpyrazone throughout $>85 \%$ of the simulation time.

Indomethacin formed weaker interactions than sulfinpyrazone as it was less stable inside the binding site through the simulation. This could also be observed from the timeline protein-ligand contacts, which are shown to be less than that of sulfinpyrazone (Figure 7). The main binding interactions were water bridged hydrogen bonds with Pro132, Cys145, Met165, Leu167, Pro168, Arg188, Gln189, Ala191, Ala193, Ala194, Gly195, and Thr196. Hydrophobic interactions were maintained with indomethacin through His164, Glu166, Leu167, Gly170, Val17, and Gln192. Hydrogen bonding interactions occurred the least in indomethacin-protein contacts, which were maintained by Pro168, Asp187, Arg188, Gln189, Thr190, and Thr196.

The protein-ligand contacts histogram of auranofin showed it to have the least contacts contribution percentage $(<20 \%)$ throughout the simulation time. Also, the timeline heat map shows auranofin to have much fewer contacts with the protein. The major contact type was water bridged hydrogen bonds, which can be explained by its abandonment of the binding site and interaction with the protein surface by hydrogen bonds through water molecules.

The N3 molecule formed a high number of contacts with binding site amino acid residues, with an interaction fraction comparable to that of sulfinpyrazone (80\%), as observed from the protein-ligand contacts histogram (Figure 6) and heat map (Figure 7). The main interacting amino acid residues were Thr24, Thr25, Thr26, His41, Ser46, Gly143, Cys145, His164, Glu166, and Gln189, with Thr26, His41, Gly143, Cys145, His164, and Glu166 contributing to most of the interactions $(>60 \%)$. The main binding interactions were found to be hydrogen and bridged hydrogen bonds. The N3 inhibitor stability during the MD simulations and higher number of contacts with the protein binding site, due to its higher number of anchorage sites, reflected its superior docking score over the remaining three NSAIDs. However, the interactions of sulfinpyrazone with the protein binding site were comparable in number and strength to that of the N3 molecule.

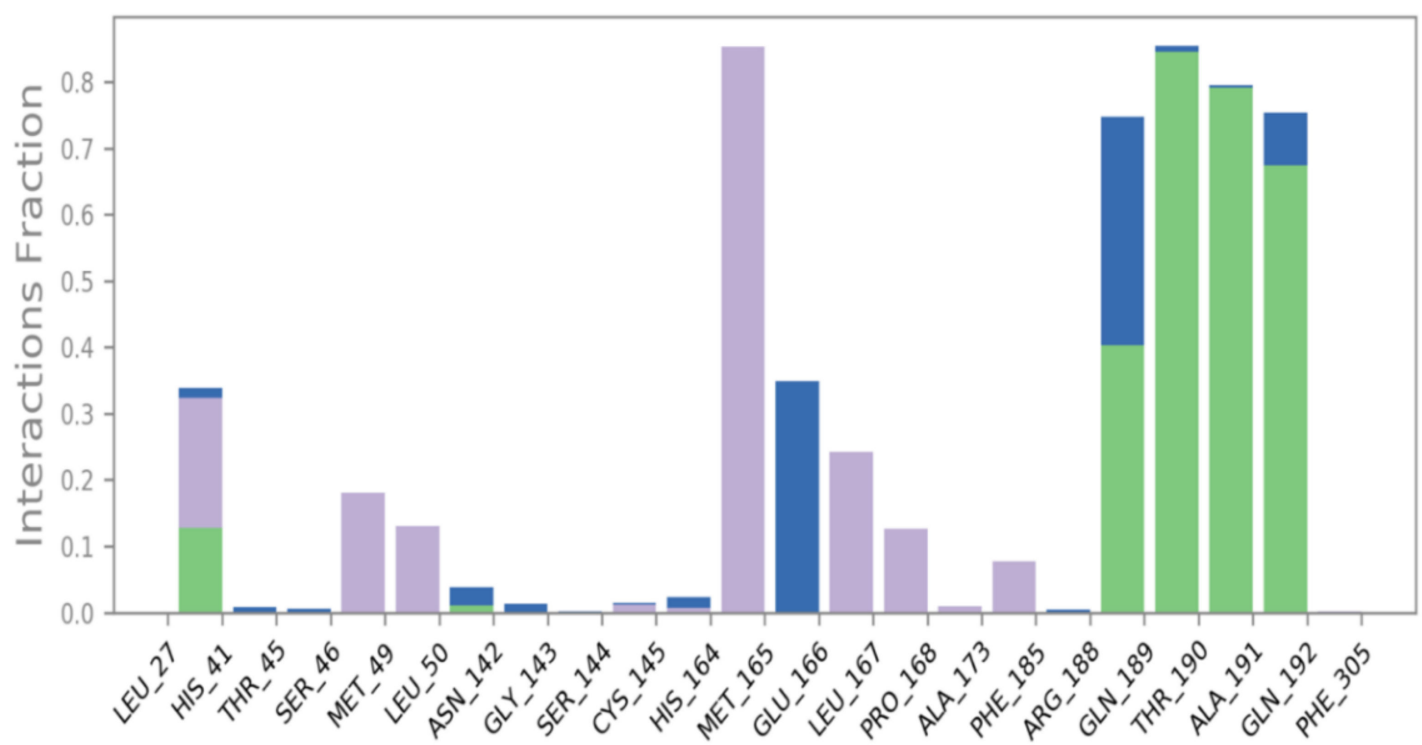

(A)

Figure 6. Cont. 


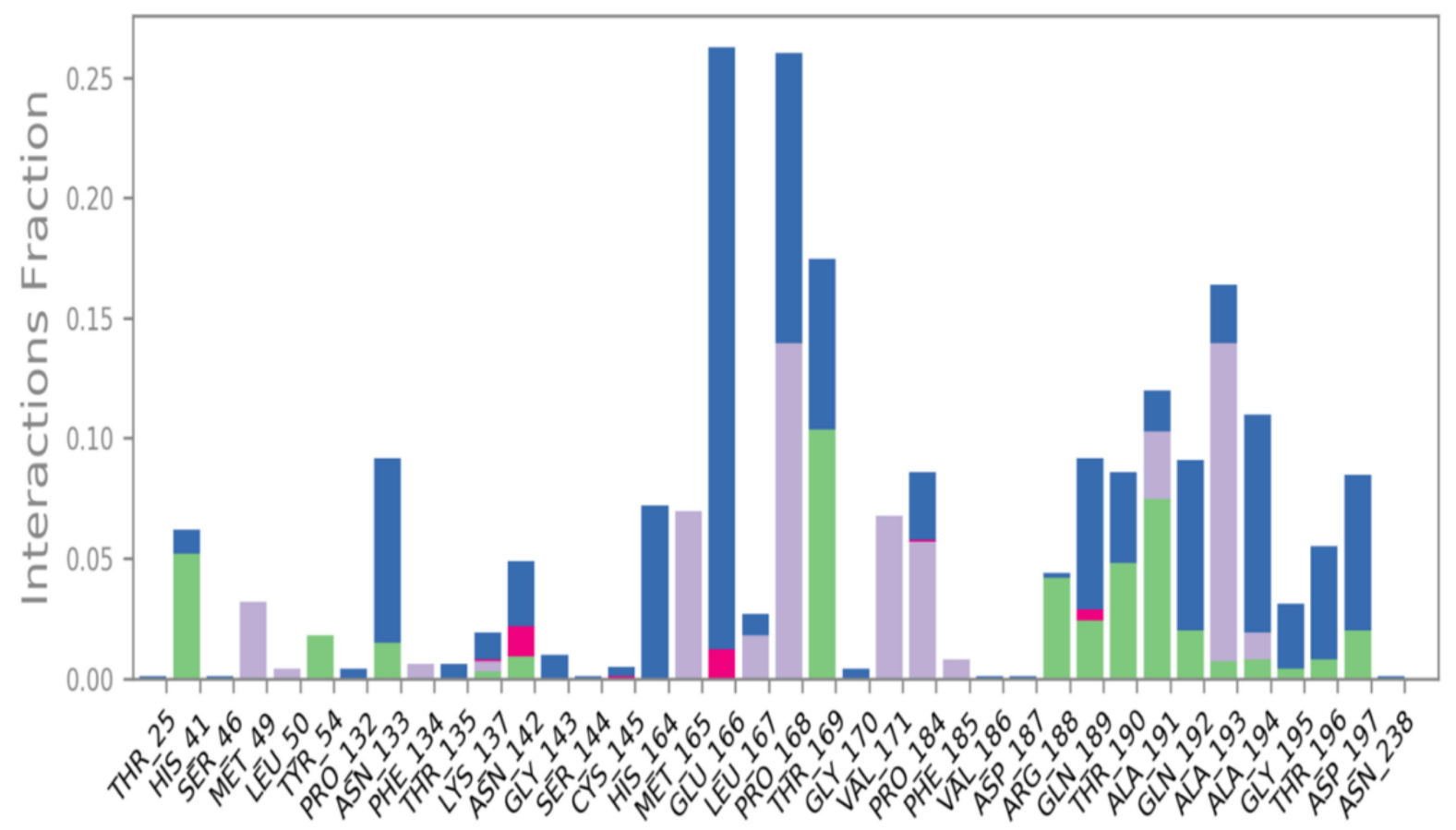

(B)

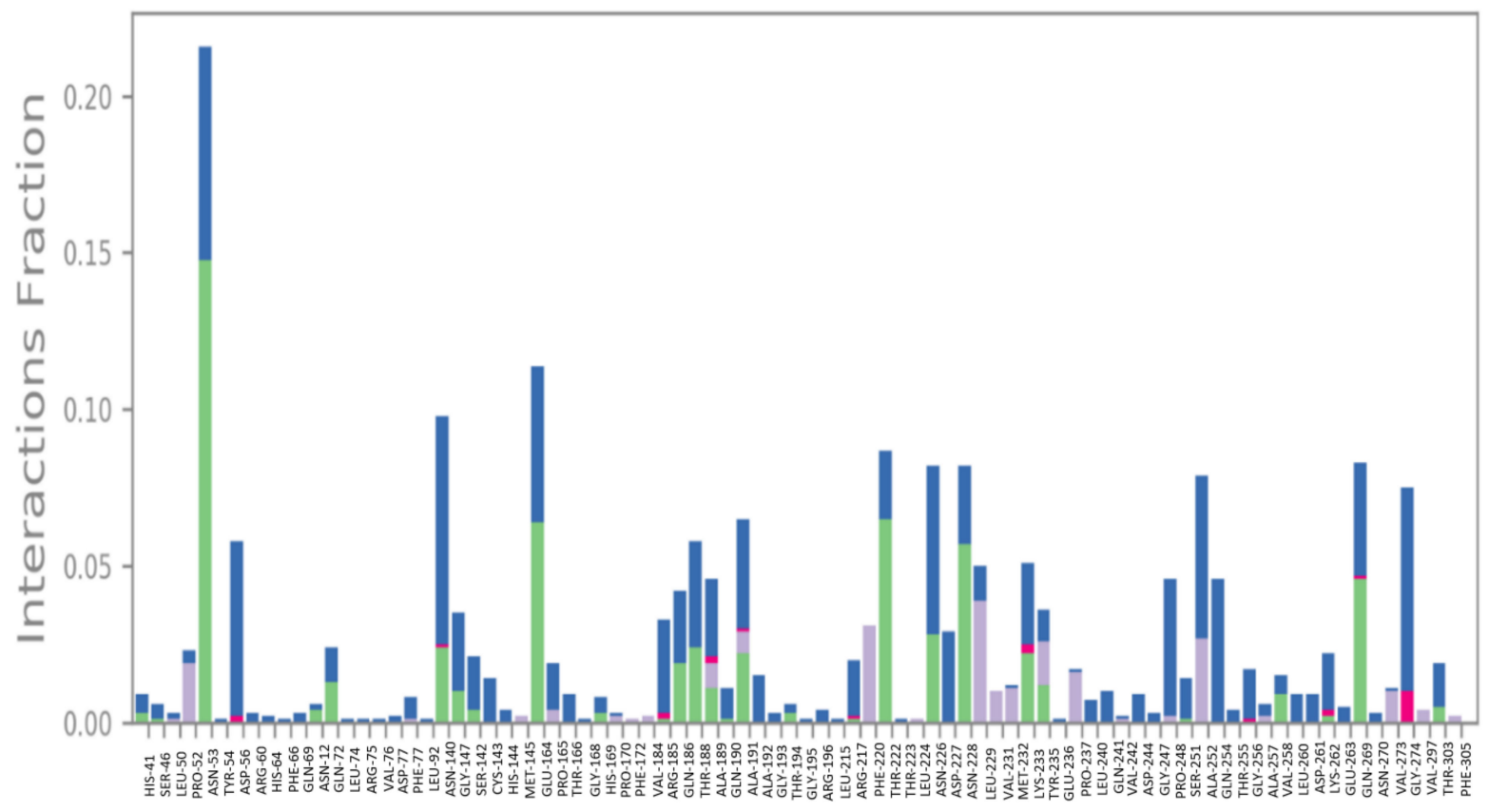

(C)

Figure 6. Cont. 


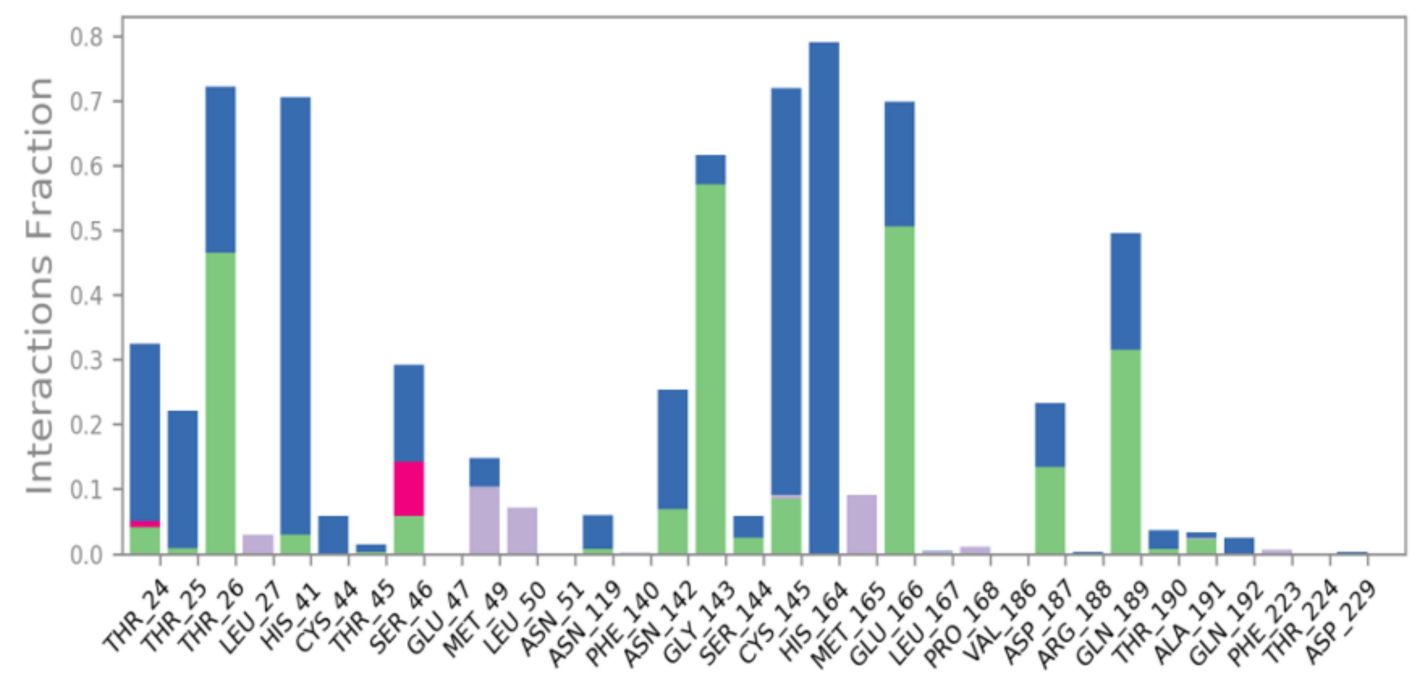

H-bonds $\square$ Hydrophobic $\square$ lonic $\square$ Water bridges

(D)

Figure 6. Protein-ligand contacts histograms for sulfinpyrazone (A), indomethacin (B), auranofin (C), and N3 (D).

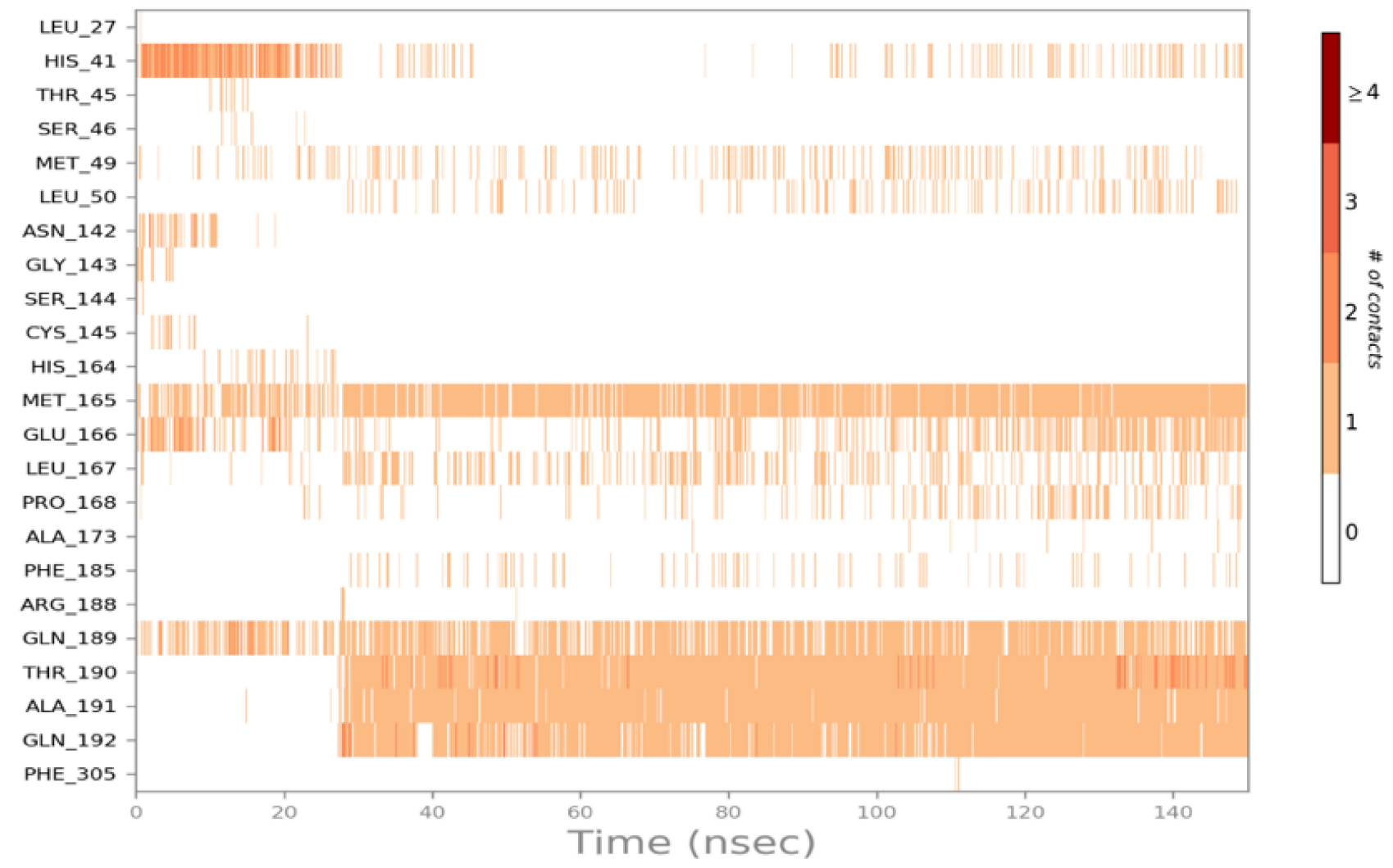

(A)

Figure 7. Cont. 


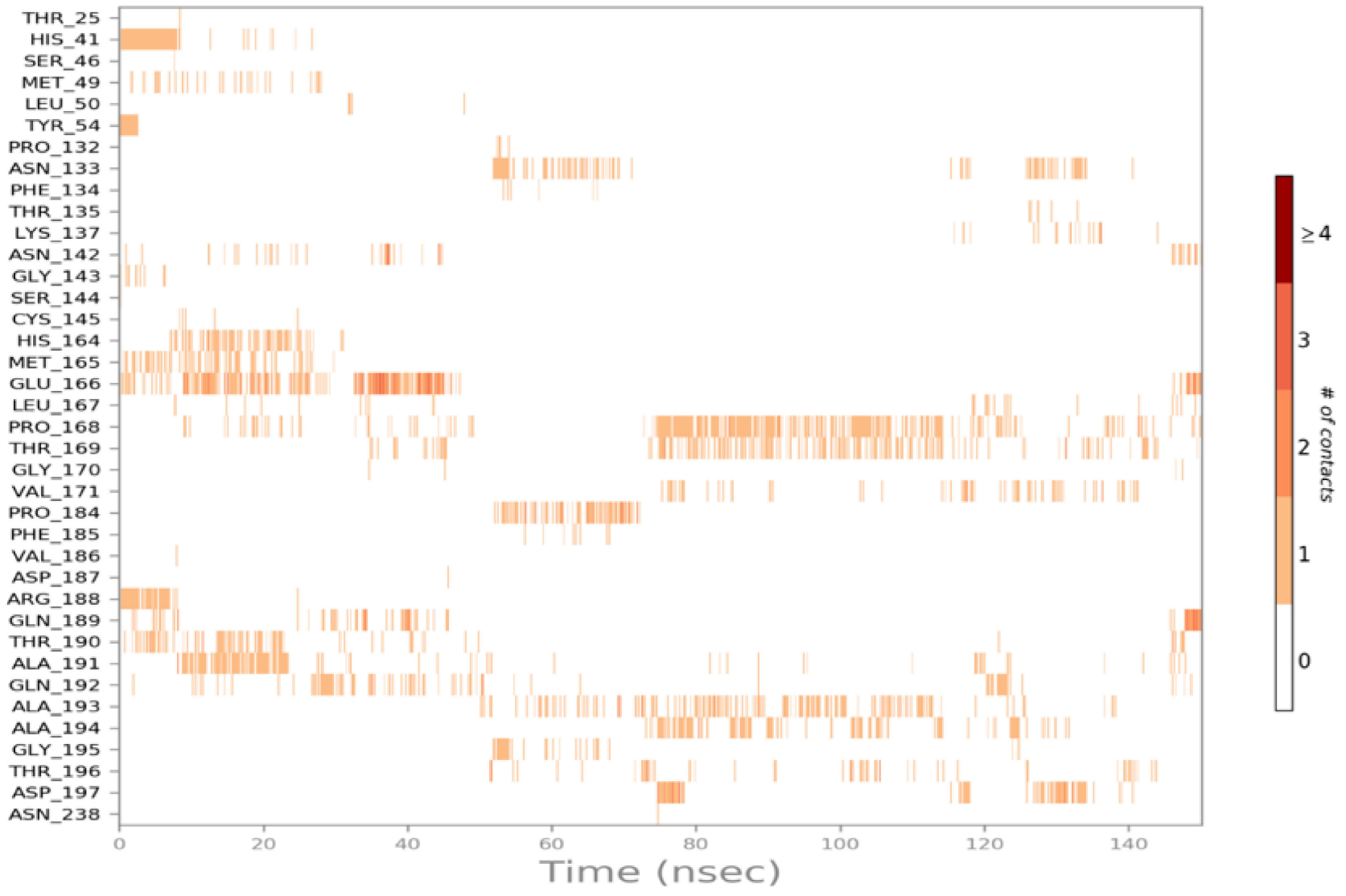

(B)

Figure 7. Cont. 


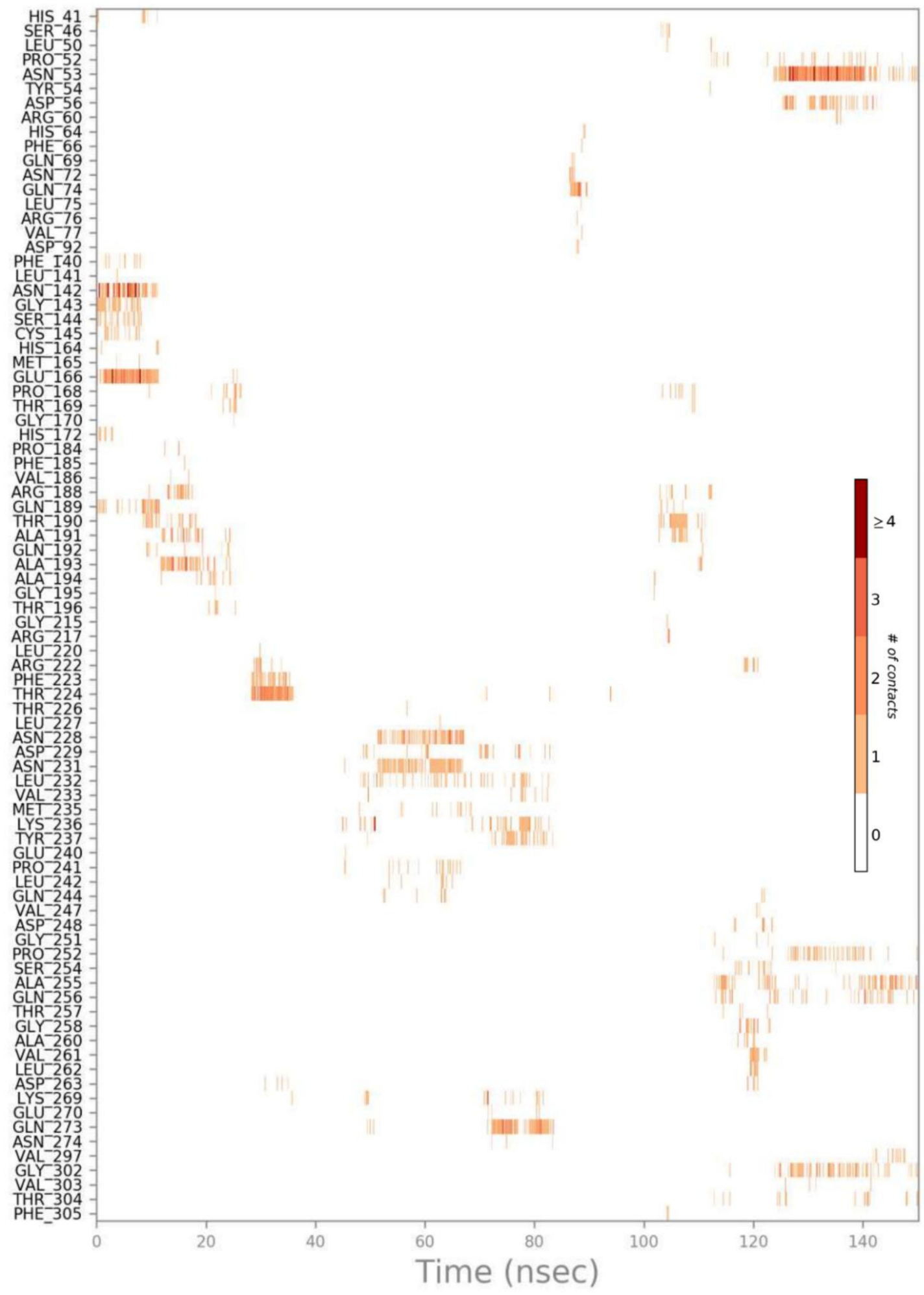

(C)

Figure 7. Cont. 


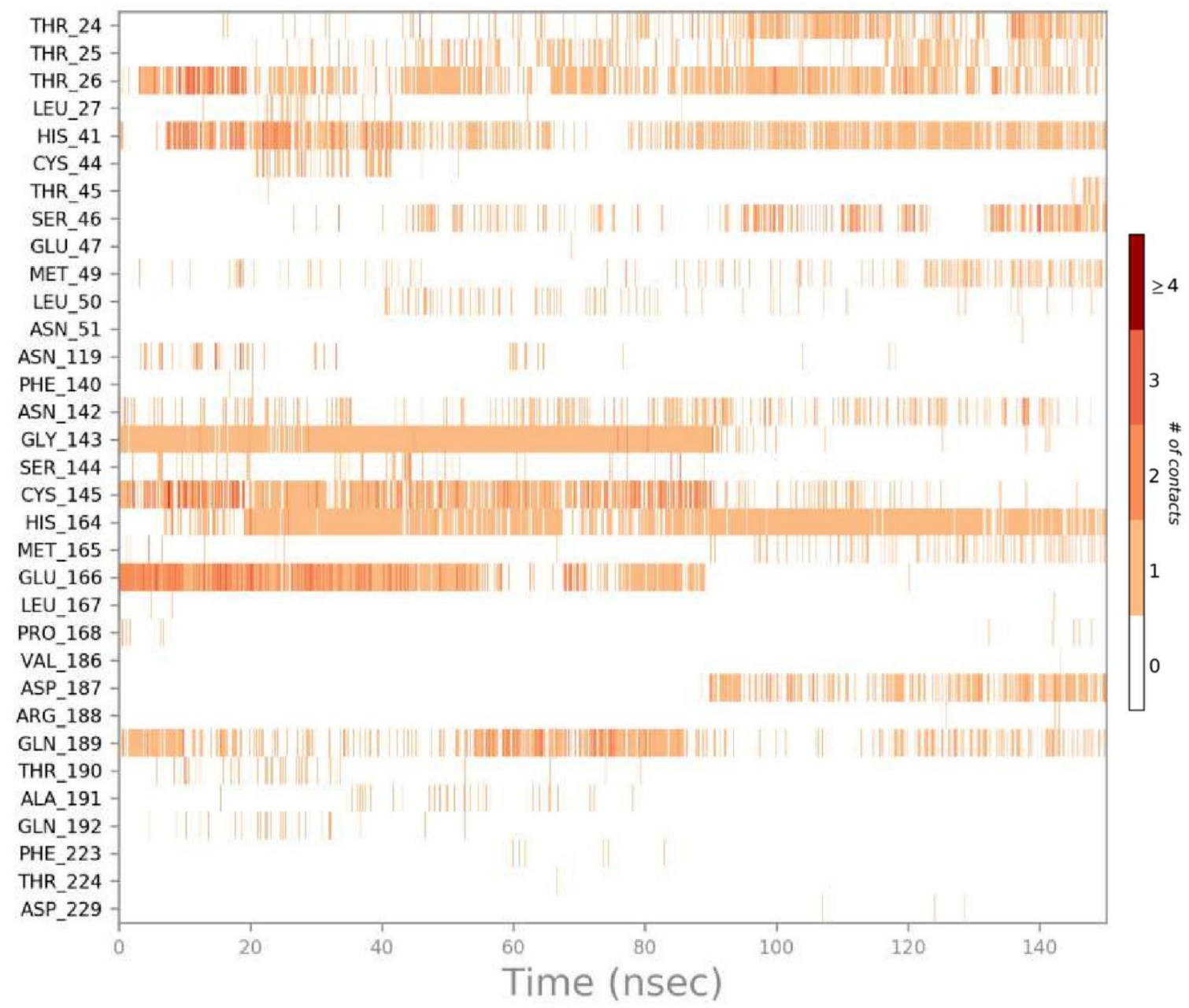

(D)

Figure 7. Heat map representing the number of protein-ligand contacts for sulfinpyrazone (A), indomethacin (B), auranofin (C), and N3 (D).

The analysis of RMSD_lig and protein-ligand contacts diagrams together suggests sulfinpyrazone to have the most stable binding with the protein, followed by indomethacin, followed by auranofin.

\subsection{Quantum Mechanical Studies}

Auranofin (AF) is a gold-based compound containing several stereoisomeric centers. It is well known that not all functionals are designed to describe the electronic properties of all atoms in the periodic table. Therefore, we herein utilized four hybrid functionals B3PW91, CAM-B3LYP, PBE1PBE, and wB97X in combination with def2tzvp for the description of the gold $(\mathrm{Au})$ atom and $6-311++\mathrm{G}^{* *}$ for the description of all $\mathrm{H}, \mathrm{C}, \mathrm{N}, \mathrm{S}$, and $\mathrm{P}$ atoms. The calculated spatial properties such as bond length and bond angle were compared with the X-ray crystallographic data of AF reported by Hill and co-workers [51]. Values of the computed parameters and the reported experimental ones are listed in Table 3. 
Table 3. Selected calculated geometric and electronic parameters of auranofin computed using different hybrid functionals in combination with def2tzvp and $6-311++G^{* *}$ basis sets.

\begin{tabular}{|c|c|c|c|c|c|}
\hline & B3PW91 & CAM-B3LYP & PBE1PBE & wB97X & Exp \\
\hline $\mathrm{Au}-\mathrm{P}(\AA)$ & 2.28 & 2.29 & 2.28 & 2.29 & 2.26 \\
\hline $\mathrm{Au}-\mathrm{S}(\AA)$ & 2.31 & 2.32 & 2.31 & 2.32 & 2.29 \\
\hline$\angle \mathrm{S}-\mathrm{Au}-\mathrm{P}$ & 177.4 & 179.2 & 178.9 & 177.4 & 173.6 \\
\hline$\angle \mathrm{Au}-\mathrm{S}-\mathrm{C}$ & 102.7 & 101.6 & 101.3 & 102.2 & 105.6 \\
\hline $\mathrm{E}_{\mathrm{h}}$ (a.u.) & -2335.103739 & -2334.956583 & -2333.714375 & -2335.316967 & - \\
\hline ZPE (a.u.) & 0.534394 & 0.540545 & 0.537098 & 0.542842 & - \\
\hline$E_{\mathrm{h}}+\mathrm{ZPE}$ (a.u.) & -2334.569345 & -2334.416038 & -2333.177278 & -2334.774126 & - \\
\hline Polarizability (a.u.) & 348.400064 & 337.552355 & 344.065746 & 334.158185 & - \\
\hline$\mu(\mathrm{D})$ & 11.5681 & 11.6597 & 11.4449 & 11.8367 & - \\
\hline HOMO-LUMO gap (eV) & 4.94 & 7.30 & 5.21 & 9.21 & - \\
\hline Entropy (cal/mol-kelvin) & 261.262 & 256.099 & 256.603 & 250.821 & - \\
\hline
\end{tabular}

Since the gold $(\mathrm{Au})$ atom is thought to be the main contributor to AF binding affinity, hence its biological activity, we mainly focused on the bond length and bond angle where the $\mathrm{Au}$ atom was involved. As can be seen in Table 3, the four functionals gave values for the bond length between the gold atom and phosphorous atom (Au-P) and between the gold atom and sulfur atom (Au-S) consistent with the experimental values (deviation by only $0.03 \AA$ ), where B3PW91 and PBE1PBE performed better (deviation by only $0.02 \AA$ ) than wB97X and CAM-B3LYP (deviation by only $0.03 \AA$ ). Regarding the bond angle between $\mathrm{Au}, \mathrm{P}$, and $\mathrm{S}$, it was noted that B3PW91 and wB97X functionals performed better than other functionals.

Other parameters were calculated for AF and listed in Table 3 as well. There were no significant discrepancies noted for the calculated parameters except for the energy gap between the lowest unoccupied molecular orbital (LUMO) and the highest occupied molecular orbital (HOMO). Calculation of HOMO and LUMO energy is of great importance as it helps in assessing the chemical reactivity of a drug at its binding site on a protein $[1,2]$. HOMO energy is a measure for the electron-donating strength of a molecule during the complex formation, while LUMO energy signifies the capacity of the electron-withdrawing of a molecule. The difference in HOMO and LUMO energy, known as HOMO-LUMO gap energy, is a measure for computing the molecular reactivity and stability of the compounds (electronic excitation energy) [3]. In other words, HOMO-LUMO plays a significant role in stabilizing the interactions between drug and target protein. Hence, the orbital energy of both HOMO and LUMO and the HOMO-LUMO energy gap were calculated to estimate the chemical reactivity of the selected compounds using DFT.

B3PW91 computed the HOMO-LUMO energy gap at $4.9385 \mathrm{eV}$ while it was calculated by $w B 97 X$ at $9.2141 \mathrm{eV}$. The discrepancy between the two values was estimated at $4.2756 \mathrm{eV}$. We therefore anticipated seeing this discrepancy reflected by the computed electronic distribution of the outermost molecular orbitals as well.

Surprisingly, the electronic density over HOMO, LUMO, and other molecular orbitals did not show a significant difference based on the functional used, except for $\mathrm{L}+2$. The diagrammatic representations of the electronic density of the outermost molecular orbitals are depicted in Figure 8. It was also noticed that the molecular electrostatic potential (MEP) map of electron density distribution at the molecular level did not show a significant discrepancy, as can be seen in Figure 8. 

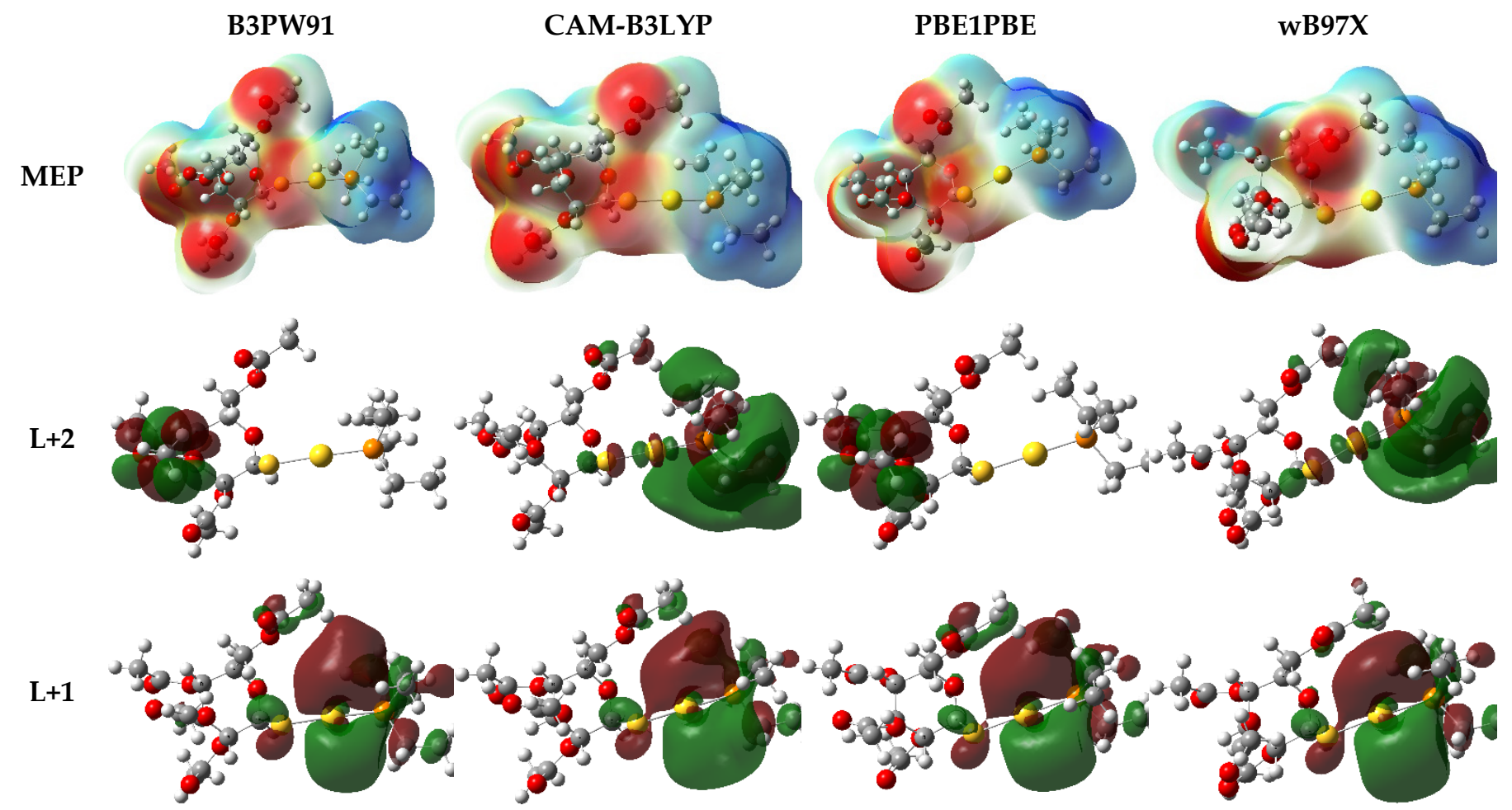

L

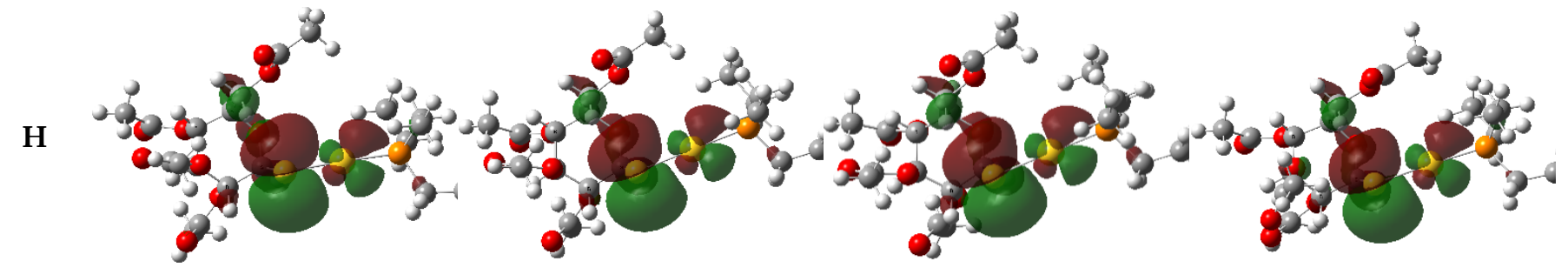

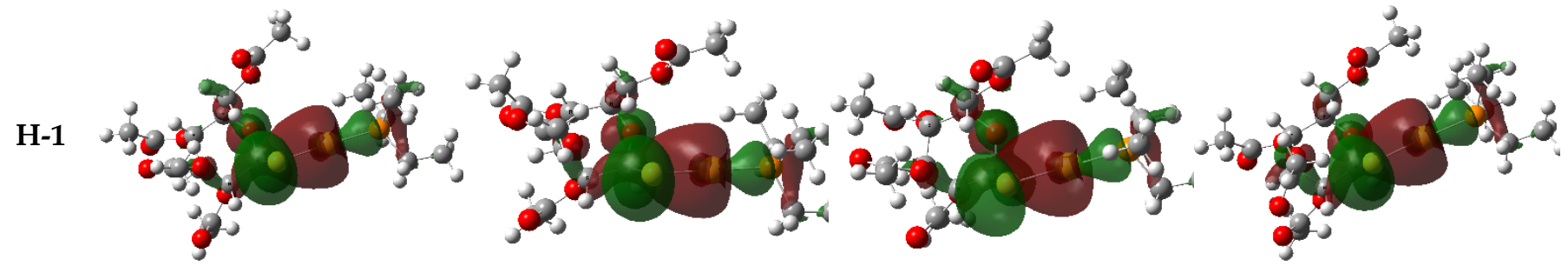

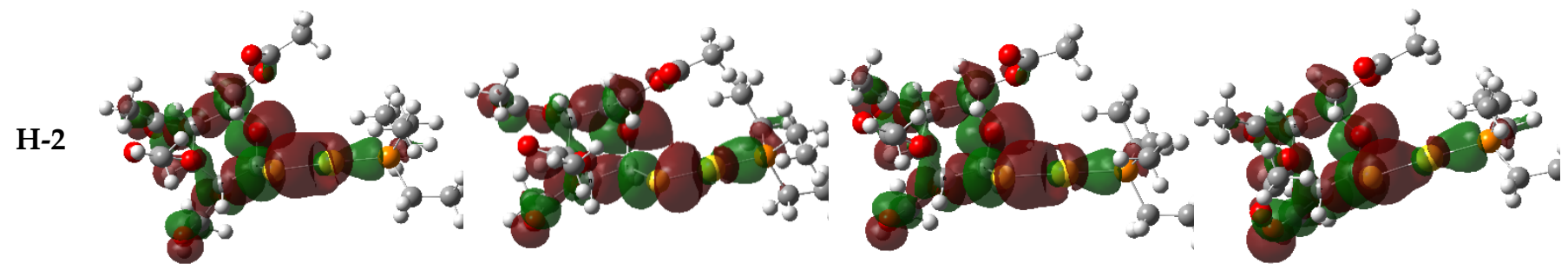

Figure 8. Electron density distribution of the molecular electrostatic potential (MEP) map and the outermost molecular orbitals of auranofin computed using different hybrid functionals in combination with def2tzvp and 6-311++ $\mathrm{G}^{* *}$ basis sets. 
Since AF structure has many chiral centers, the electronic circular dichroism spectrum (ECD) was also calculated to validate the performance of hybrid functionals. Each functional gave a distinct ECD spectrum where the position and intensity of peaks differed significantly. The ECD spectrum of AF is deposited in Figure 9.

B3PW91

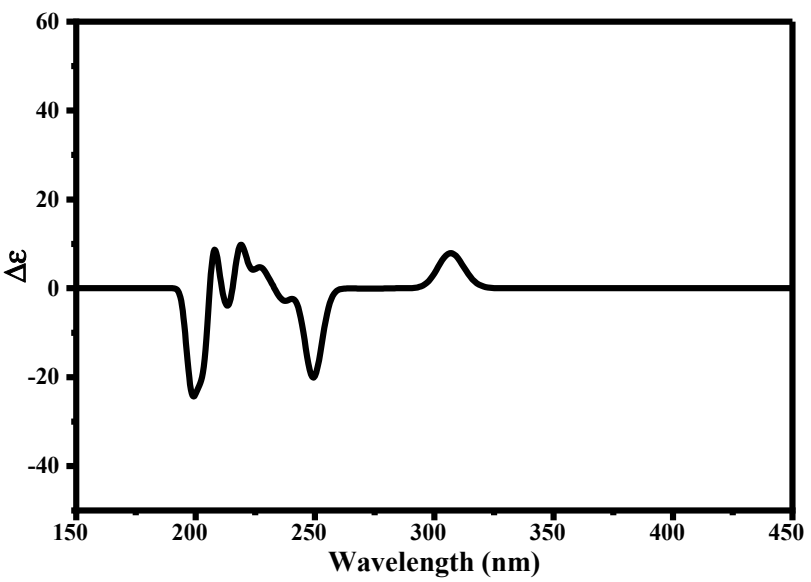

PBE1PBE

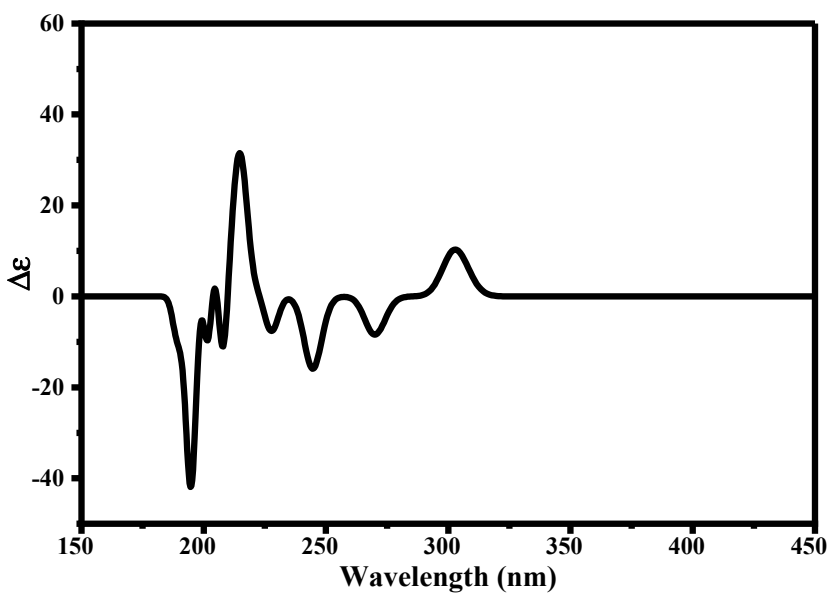

CAM-B3LYP

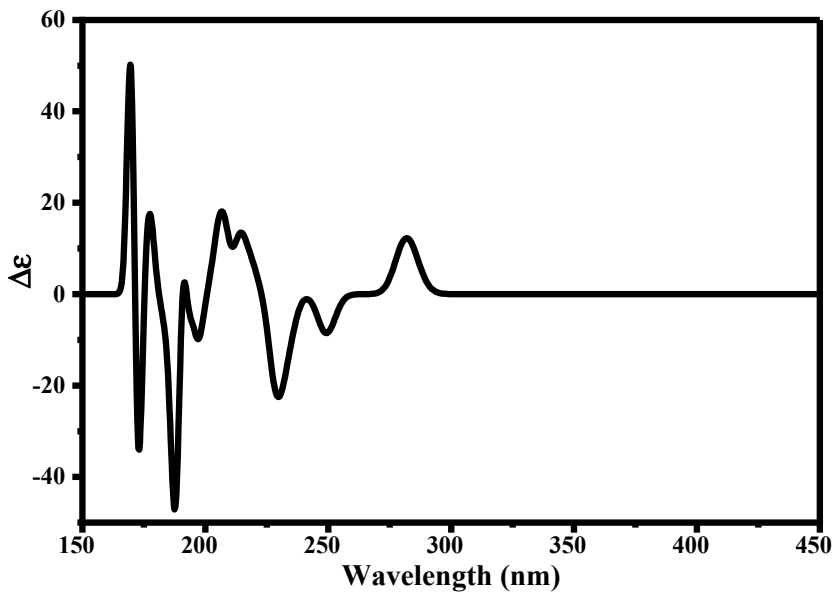

wB97X

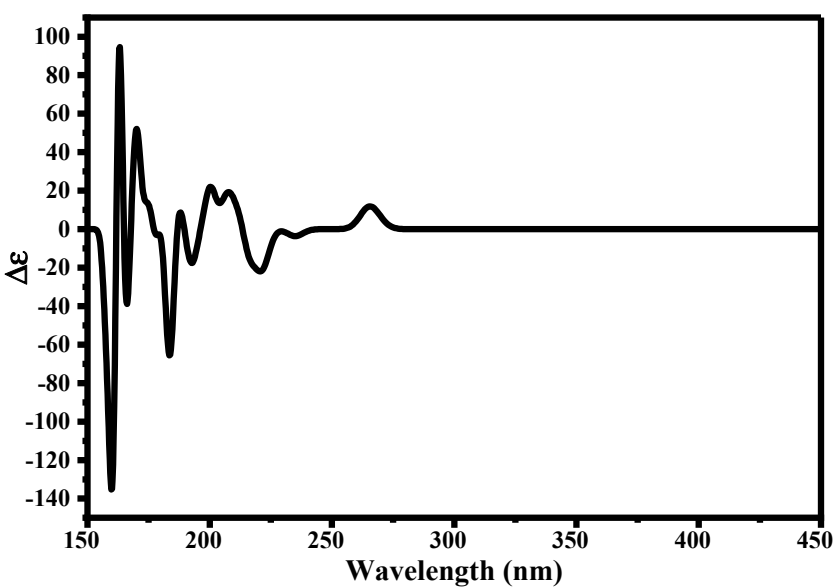

Figure 9. Computed electronic circular dichroism (ECD) of auranofin computed using different hybrid functionals in combination with def2tzvp and 6-311++ $\mathrm{G}^{* *}$ basis sets.

\subsection{Structure-Activity Relationship Studies}

NSAIDs can be classified according to their chemical structures [52] into:

I. Salicylic acid derivatives: (Sulfasalazine 7, Salsalate 29, Diflunisal 36, and Aspirin 38).

II. $p$-Amino phenol derivatives: (Phenacetin 35 and Paracetamol 40).

III. Pyrazolidine dione derivatives: (Sulfinpyrazone 2, Phenylbutazone 5, and Oxyphenbutazone 8).

IV. Anthranilic acid derivatives: (Flufenamic acid 31, Mefenamic acid 32, and Meclofenamic acid 34).

V. Aryl alkanoic acid derivatives:

a. Indole acetic acid: (Indomethacin 3).

b. Indene acetic acid: (Sulindac 9).

c. Pyrrole acetic acid: (Zomepirac $\mathbf{1 6}$ and Tolmetin 22).

d. Phenyl acetic (propionic) acid: (Oxaprozin 12, Etodolac 18, Carprofen 20, Ketoprofen 21, Ketorolac 25, Ibuprofen 26, Fenoprofen 27, Flurbiprofen 28, Naproxen 30, and Diclofenac 33). 
VI. Oxicams: (Meloxicam 11, Piroxicam 14, and Tenoxicam 19).

VII. Selective COX-2 inhibitors: (Celecoxib 6, Valdecoxib 15, and Rofecoxib 17).

VIII. Gold compounds: (Auranofin 4, Aurothioglucose 37, and Aurothiomalate sodium 39).

IX. Miscellaneous: (Metamizole 10, Nimesulide 13, Nabumetone 23, Probenecid 24, and Allopurinol 41).

So, based on their stabilities and binding scores to the SARS-CoV-2 main protease, we could identify the structure-activity relationships of the tested NSAIDs which, interestingly, showed the following results (Figure 10):

(a) Concerning salicylic acid derivatives, the best activity was attained by maintaining a salicylic acid scaffold without -OH or - $\mathrm{COOH}$ substitution, yet it was preferable to substitute a phenyl ring at the para position to -OH of the salicylic scaffold to ensure the best activity (compound 7).

(b) In addition, for $p$-Amino phenol derivatives, better activity was achieved when phenolic $-\mathrm{OH}$ was substituted by ethyl group (compound 35 ) than unsubstituted one (compound 40).

(c) For pyrazolidine dione NSAIDs, the best activity was accomplished by substitution of a pyrazolidine ring at position 4 by [2-(phenylsulfinyl)ethyl] moiety (compound 2).

(d) Moreover, studying the structure-activity relationship for anthranilic acid derivatives revealed that substitution of a phenyl ring attached to the anthranilic acid scaffold by trifluoromethyl group at position 3 attained the best activity (compound 31).

(e) Furthermore, concerning aryl acetic/propionic acid derivatives, the best activity was attained when the indole acetic acid drug was used (compound 3 ).

(f) For oxicams better activity was accomplished when $2 \mathrm{H}-1,2$-benzothiazine nucleus (compounds 11 and 14) was used rather than 2,3-dihydro-4H-thieno[2,3-e] [1,2] thiazine (compound 19).

(g) On the other hand, with regards to selective cox-2 inhibitors, it worth noting that substitution of a benzenesulfonamide scaffold at position 4 with 3-trifluoromethyl pyrazole moiety (compound 6 ) showed better activity than 5-methyl isoxazole moiety (compound 15) and 5H-furan-2-one (compound 17).

(h) Additionally, for gold anti-inflammatory compounds, the best activity was attained when gold was attached to 3,4,5-triacetyloxy-6-(acetyloxymethyl) oxane-2-thiolate moiety (compound 4). 


\section{SAR}

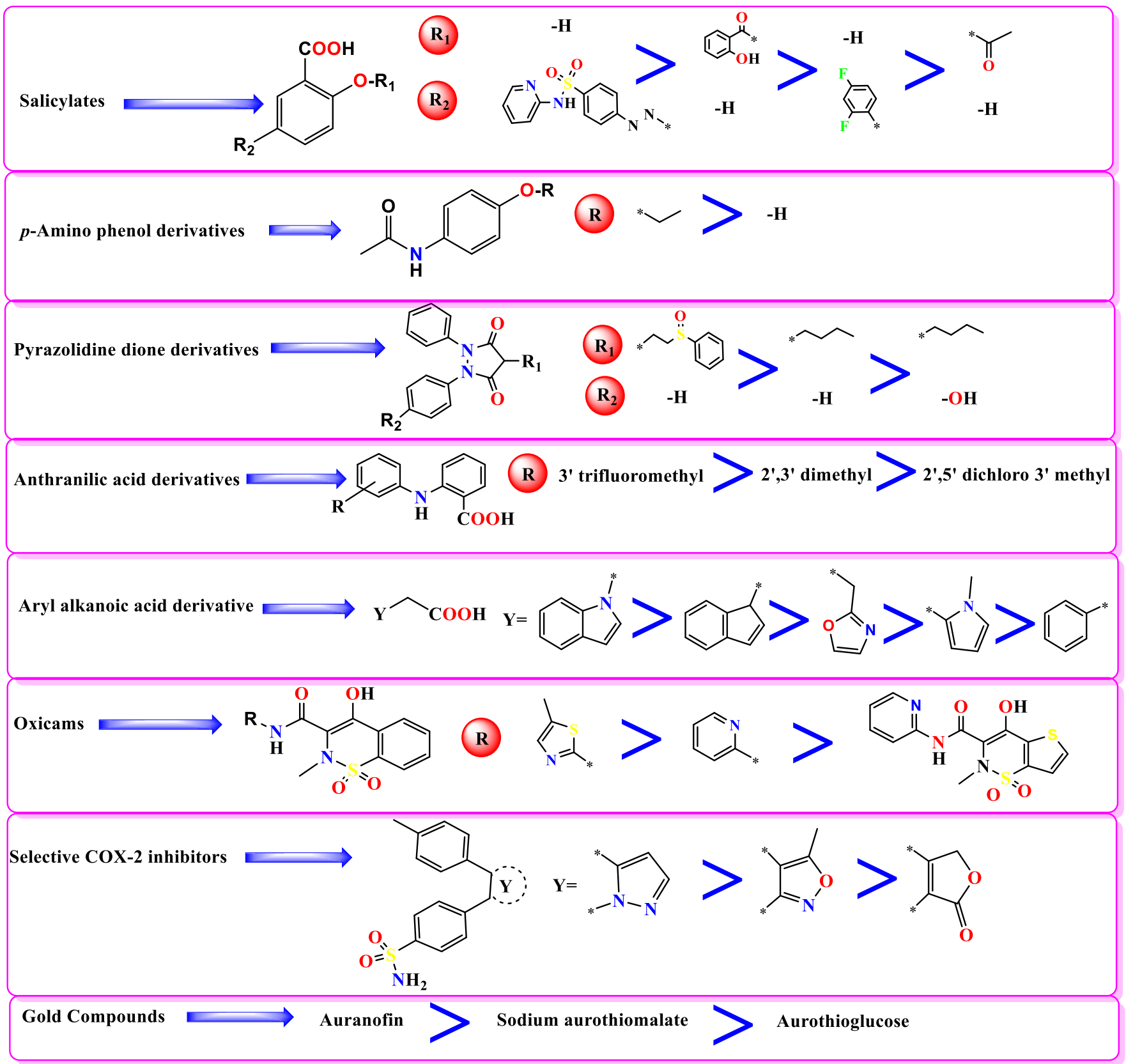

Figure 10. Structure-Activity Relationship (SAR) studies of the studied FDA-approved NSAIDs (2-41) according to their binding potentials towards the SARS-CoV-2 Mpro.*: The connection point to the main molecule.

\section{Conclusions}

This study revealed the potential of repurposing NSAIDs to bind to the active site of the SARS-CoV-2 main protease. Molecular docking studies revealed the stability and conformational flexibility of most of these drugs in the enzyme active site. Three of the screened drugs (sulfinpyrazone 2 , indomethacin 3 , and auranofin 4 ) showed the strongest binding affinities and the best binding modes as well. Furthermore, molecular dynamics simulations were performed for the most promising members from the docking studies 
$(2,3$, and 4$)$ and confirmed our docking results as being promising SARS-CoV-2 main protease inhibitors. The quantum mechanical studies revealed that the hybrid functional B3PW91 provided a good description of the spatial parameters of AF. Moreover, NSAIDs may be used by medicinal chemists as lead compounds for the development of potent SARS-CoV-2 ( $\left.\mathrm{M}^{\text {pro }}\right)$ inhibitors. As a result, we can prioritize some NSAIDs as recommended over others in the treatment of inflammation accompanying COVID-19.

Author Contributions: Conceptualization, methodology, original draft preparation A.A.E., M.I.I. and M.K.; writing-review and editing, M.I.A.H. and E.B.E.; project administration, H.S.A.; supervision, project administration, writing-review and editing, A.A.A.-K. All authors have read and agreed to the published version of the manuscript.

Funding: No funding was received for this study.

Institutional Review Board Statement: Not applicable.

Informed Consent Statement: Not applicable.

Data Availability Statement: The data presented in this study are available on request from the corresponding author.

Conflicts of Interest: The authors declare no competing interest.

Sample Availability: Not available.

\section{References}

1. WHO. Coronavirus Disease (COVID-19) Pandemic. 2021. Available online: https://www.who.int/emergencies/diseases/novelcoronavirus-2019?gclid=Cj0KCQjw38-DBhDpARIsADJ3kjmxpTjUS_7o4K1orvnoq-MfSNKEhLJ1_TeOoN6DlYz3RBAC8hfU_ rQaAsNwEALw_wcB (accessed on 11 April 2021).

2. Worldometer. Coronavirus. 2021. Available online: https://www.worldometers.info/coronavirus/?utm_campaign= homeAdvegas1? (accessed on 11 April 2021).

3. Chen, J.; Wang, Y.K.; Gao, Y.; Hu, L.S.; Yang, J.W.; Wang, J.R.; Sun, W.J.; Liang, Z.Q.; Cao, Y.M.; Cao, Y.B. Protection against COVID-19 injury by qingfei paidu decoction via anti-viral, anti-inflammatory activity and metabolic programming. Biomed. Pharmacother. 2020, 129, 110281. [CrossRef] [PubMed]

4. Sarhan, A.A.; Ashour, N.A.; Al-Karmalawy, A.A. The journey of antimalarial drugs against SARS-CoV-2: Review article. Inform. Med. Unlocked 2021, 24, 100604. [CrossRef] [PubMed]

5. Pushpakom, S.; Iorio, F.; Eyers, P.A.; Escott, K.J.; Hopper, S.; Wells, A.; Doig, A.; Guilliams, T.; Latimer, J.; McNamee, C. Drug repurposing: Progress, challenges and recommendations. Nat. Rev. Drug Dis. 2019, 18, 41-58. [CrossRef] [PubMed]

6. Khattab, M.; Al-Karmalawy, A.A. Revisiting Activity of Some Nocodazole Analogues as a Potential Anticancer Drugs Using Molecular Docking and DFT Calculations. Front. Chem. 2021, 9, 92. [CrossRef]

7. Talevi, A.; Bellera, C.L. Challenges and opportunities with drug repurposing: Finding strategies to find alternative uses of therapeutics. Expert Opin. Drug Dis. 2020, 15, 397-401. [CrossRef]

8. Masoudi-Sobhanzadeh, Y.; Omidi, Y.; Amanlou, M.; Masoudi-Nejad, A. Drug databases and their contributions to drug repurposing. Genomics 2020, 112, 1087-1095. [CrossRef]

9. Brogi, S. Computational approaches for drug discovery. Molecules 2019, 24, 3061. [CrossRef]

10. Lin, X.; Li, X.; Lin, X. A review on applications of computational methods in drug screening and design. Molecules 2020, 25, 1375. [CrossRef]

11. Tay, M.Z.; Poh, C.M.; Rénia, L.; MacAry, P.A.; Ng, L.F. The trinity of COVID-19: Immunity, inflammation and intervention. Nat. Rev. Immunol. 2020, 20, 363-374. [CrossRef] [PubMed]

12. Zhang, W.; Zhao, Y.; Zhang, F.; Wang, Q.; Li, T.; Liu, Z.; Wang, J.; Qin, Y.; Zhang, X.; Yan, X.; et al. The use of anti-inflammatory drugs in the treatment of people with severe coronavirus disease 2019 (COVID-19): The Perspectives of clinical immunologists from China. Clin. Immunol. 2020, 214, 108393. [CrossRef] [PubMed]

13. Kosuge, M.; Furusawa-Nishii, E.; Ito, K.; Saito, Y.; Ogasawara, K. Point mutation bias in SARS-CoV-2 variants results in increased ability to stimulate inflammatory responses. Sci. Rep. 2020, 10, 1-9. [CrossRef]

14. Russell, B.; Moss, C.; Rigg, A.; Van Hemelrijck, M. COVID-19 and treatment with NSAIDs and corticosteroids: Should we be limiting their use in the clinical setting? Ecancermedicalscience 2020, 14. [CrossRef] [PubMed]

15. Guererero, C.A.; Murillo, A.; Acosta, O. Inhibition of rotavirus infection in cultured cells by N-acetyl-cysteine, PPAR $\gamma$ agonists and NSAIDs. Antivir. Res. 2012, 96, 1-12. [CrossRef] [PubMed]

16. Madeira, J.M.; Gibson, D.L.; Kean, W.F.; Klegeris, A. The biological activity of auranofin: Implications for novel treatment of diseases. Inflammopharmacology 2012, 20, 297-306. [CrossRef] 
17. Mostafa, A.; Kandeil, A.; Elshaier, Y.A.M.M.; Kutkat, O.; Moatasim, Y.; Rashad, A.A.; Shehata, M.; Gomaa, M.R.; Mahrous, N.; Mahmoud, S.H.; et al. FDA-Approved Drugs with Potent In Vitro Antiviral Activity against Severe Acute Respiratory Syndrome Coronavirus 2. Pharmaceuticals 2020, 13, 443. [CrossRef] [PubMed]

18. Alnajjar, R.; Mostafa, A.; Kandeil, A.; Al-Karmalawy, A.A. Molecular docking, molecular dynamics, and in vitro studies reveal the potential of angiotensin II receptor blockers to inhibit the COVID-19 main protease. Heliyon 2020, 6, e05641. [CrossRef]

19. Zaki, A.A.; Al-Karmalawy, A.A.; El-Amier, Y.A.; Ashour, A. Molecular docking reveals the potential of Cleome amblyocarpa isolated compounds to inhibit COVID-19 virus main protease. New J. Chem. 2020, 44, 16752-16758. [CrossRef]

20. Elmaaty, A.A.; Alnajjar, R.; Hamed, M.I.; Khattab, M.; Khalifa, M.M.; Al-Karmalawy, A.A. Revisiting activity of some glucocorticoids as a potential inhibitor of SARS-CoV-2 main protease: Theoretical study. RSC Adv. 2021, 11, 10027-10042. [CrossRef]

21. Eissa, I.; Al-Karmalawy, A.; Dahab, M.A.; Metwaly, A.M.; Elhady, S.S.; Elkaeed, E.B.; Darwish, K.M. Molecular docking and dynamics simulation revealed the potential inhibitory activity of ACEIs against SARS-CoV-2 targeting hACE2 receptor. Front. Chem. 2021, 9, 227.

22. Al-Karmalawy, A.A.; Alnajjar, R.; Dahab, M.; Metwaly, A.; Eissa, I. Molecular docking and dynamics simulations reveal the potential of anti-HCV drugs to inhibit COVID-19 main protease. Pharm. Sci. 2021, 9, 661230. [CrossRef]

23. Zaki, A.A.; Ashour, A.; Elhady, S.S.; Darwish, K.M.; Al-Karmalawy, A.A. Calendulaglycoside A Showing Potential Activity Against SARS-CoV-2 Main Protease: Molecular Docking, Molecular Dynamics, and SAR Studies. J. Tradit. Complement. Med. 2021, in press. [CrossRef]

24. Soltane, R.; Chrouda, A.; Mostafa, A.; Al-Karmalawy, A.; Chouaiib, K.; Dhahri, A.; Pashameah, R.; Alasiri, A.; Kutkat, O.; Shehata, M.; et al. Strong Inhibitory Activity and Action Modes of Synthetic Maslinic Acid Derivative on Highly Pathogenic Coronaviruses: COVID-19 Drug Candidate. Pathogens 2021, 10, 623. [CrossRef]

25. Elmaaty, A.A.; Darwish, K.M.; Khattab, M.; Elhady, S.S.; Salah, M.; Hamed, M.I.; Al-Karmalawy, A.A.; Saleh, M.M. In a search for potential drug candidates for combating COVID-19: Computational study revealed salvianolic acid B as a potential therapeutic targeting 3CLpro and spike proteins. J. Biomol. Struct. Dyn. 2021, 1-28. [CrossRef] [PubMed]

26. Jin, Z.; Du, X.; Xu, Y.; Deng, Y.; Liu, M.; Zhao, Y.; Zhang, B.; Li, X.; Zhang, L.; Peng, C.; et al. Structure of M pro from SARS-CoV-2 and discovery of its inhibitors. Nature 2020, 582, 289-293. [CrossRef]

27. Borges, R.S.; Palheta, I.C.; Ota, S.S.B.; Morais, R.B.; Barros, V.A.; Ramos, R.S.; Silva, R.C.; Costa, J.D.S.; Silva, C.H.T.P.; Campos, J.M.; et al. Toward of Safer Phenylbutazone Derivatives by Exploration of Toxicity Mechanism. Molecules 2019, 24, 143. [CrossRef]

28. Aceves-Hernandez, J.; Nicolás-Vázquez, I.; Aceves, F.; Hinojosa-Torres, J.; Paz, M.; Castaño, V. Indomethacin polymorphs: Experimental and conformational analysis. J. Pharm. Sci. 2009, 98, 2448-2463. [CrossRef] [PubMed]

29. Xu, L.; Li, Y.; Jing, P.; Xu, G.; Zhou, Q.; Cai, Y.; Deng, X. Terahertz spectroscopic characterizations and DFT calculations of indomethacin cocrystals with nicotinamide and saccharin. Spectrochim. Acta Part A: Mol. Biomol. Spectrosc. 2021, $249,119309$. [CrossRef]

30. Chemical Computing Group. Molecular Operating Environment (MOE), 2019.01; Chemical Computing Group ULC: Montreal, QC, Canada, 2021.

31. Release, S. 3: Desmond Molecular Dynamics System, DE Shaw Research; Maestro-Desmond Interoperability Tools; Schrödinger: New York, NY, USA, 2017.

32. Al-Karmalawy, A.A.; Khattab, M. Molecular modelling of mebendazole polymorphs as a potential colchicine binding site inhibitor. New J. Chem. 2020, 44, 13990-13996. [CrossRef]

33. Ghanem, A.A.; Emara, H.A.; Muawia, S.; El Maksoud, A.I.A.; Al-Karmalawy, A.A.; Elshal, M.F. Tanshinone IIA synergistically enhances the antitumor activity of doxorubicin by interfering with the PI3K/AKT/mTOR pathway and inhibition of topoisomerase II: In vitro and molecular docking studies. New J. Chem. 2020, 44, 17374-17381. [CrossRef]

34. Samra, R.M.; Soliman, A.F.; Zaki, A.A.; Ashour, A.; Al-Karmalawy, A.A.; Hassan, M.A.; Zaghloul, A.M. Bioassay-guided isolation of a new cytotoxic ceramide from Cyperus rotundus L. S. Afr. J. Bot. 2021, 139, 210-216. [CrossRef]

35. Davis, I.W.; Baker, D. RosettaLigand Docking with Full Ligand and Receptor Flexibility. J. Mol. Biol. 2009, 385, 381-392. [CrossRef] [PubMed]

36. Eliaa, S.G.; Al-Karmalawy, A.A.; Saleh, R.M.; ElShal, M.F. Empagliflozin and Doxorubicin Synergistically Inhibit the Survival of Triple-Negative Breast Cancer Cells via Interfering with the mTOR Pathway and Inhibition of Calmodulin: In Vitro and Molecular Docking Studies. ACS Pharmacol. Transl. Sci. 2020, 3, 1330-1338. [CrossRef]

37. Neria, E.; Fischer, S.; Karplus, M. Simulation of activation free energies in molecular systems. J. Chem. Phys. 1996, 105, 1902-1921. [CrossRef]

38. Jorgensen, W.L.; Chandrasekhar, J.; Madura, J.; Impey, R.W.; Klein, M.L. Comparison of simple potential functions for simulating liquid water. J. Chem. Phys. 1983, 79, 926-935. [CrossRef]

39. Schrödinger. Desmond Molecular Dynamics System, DE Shaw Research: New York, 2015; Schrödinger: New York, NY, USA, 2015.

40. Harder, E.; Damm, W.; Maple, J.R.; Wu, C.; Reboul, M.; Xiang, J.Y.; Wang, L.; Lupyan, D.; Dahlgren, M.K.; Knight, J.L.; et al. OPLS3: A Force Field Providing Broad Coverage of Drug-like Small Molecules and Proteins. J. Chem. Theory Comput. 2016, 12, 281-296. [CrossRef] [PubMed]

41. Martyna, G.J.; Klein, M.L.; Tuckerman, M. Nosé-Hoover chains: The canonical ensemble via continuous dynamics. J. Chem. Phys. 1992, 97, 2635-2643. [CrossRef] 
42. Martyna, G.J.; Tobias, D.J.; Klein, M.L. Constant pressure molecular dynamics algorithms. J. Chem. Phys. 1994, 101, 4177-4189. [CrossRef]

43. Frisch, M.J.; Trucks, G.W.; Schlegel, H.B.; Scuseria, G.E.; Robb, M.A.; Cheeseman, J.R.; Scalmani, G.; Barone, V.; Mennucci, B.; Petersson, G.A.; et al. Gaussian 09, Revision C.01; Gaussian, Inc.: Wallingford, CT, USA, 2009.

44. Perdew, J.P.; Wang, Y. Accurate and simple analytic representation of the electron-gas correlation energy. Phys. Rev. B 1992, 45, 13244-13249. [CrossRef] [PubMed]

45. Yanai, T.; Tew, D.; Handy, N.C. A new hybrid exchange-correlation functional using the Coulomb-attenuating method (CAMB3LYP). Chem. Phys. Lett. 2004, 393, 51-57. [CrossRef]

46. Ropo, M.; Kokko, K.; Vitos, L. Proving the Perdew-Burke-Ernzerhof density functional designed for metallic bulk and surface systems. Mater. Sci. 2007, 77, 195445. [CrossRef]

47. Austin, A.J.; Petersson, G.A.; Frisch, M.J.; Dobek, F.J.; Scalmani, G.; Throssell, K. A Density Functional with Spherical Atom Dispersion Terms. J. Chem. Theory Comput. 2012, 8, 4989-5007. [CrossRef] [PubMed]

48. Schäfer, A.; Horn, H.; Ahlrichs, R. Fully optimized contracted Gaussian basis sets for atoms Li to Kr. J. Chem. Phys. 1992, 97, 2571-2577. [CrossRef]

49. Schäfer, A.; Huber, C.; Ahlrichs, R. Fully optimized contracted Gaussian basis sets of triple zeta valence quality for atoms Li to Kr. J. Chem. Phys. 1994, 100, 5829-5835. [CrossRef]

50. McLean, A.D.; Chandler, G.S. Contracted Gaussian basis sets for molecular calculations. I. Second row atoms, Z=11-18. J. Chem. Phys. 1980, 72, 5639-5648.

51. Hill, D.; Sutton, B. Gold. C20H34AuO9P5. Cryst. Struct. Commun. 1980, 9, 679-686.

52. Alagarsamy, V. Textbook of Medicinal Chemistry; CBS Publishers and Distributors: New Delhi, India, 2018 ; Volume 2. 